\title{
Reducing the seismic vulnerability of existing elevated silos by means of base isolation devices
}

\author{
Alper Kanyilmaz *, Carlo Andrea Castiglioni
}

Department of Architecture, Built Environment and Construction Engineering, Politecnico di Milano, Italy

Neapolis University Pafos, Cyprus

\begin{abstract}
Industrial silos are used for storing a huge range of different materials. In the last decades, many of these structures were damaged by natural events, among which the earthquakes were the most significant. Indeed, numerous industrial plants have been built in the territories with high seismicity risk. Most of these plants have been designed and built before the latest updates of the seismic design codes took place, hence their current seismic reliability is questionable. In order to avoid future economic, life-safety and environmental troubles that can be caused by the collapse of these non-building structures, specific retrofitting solutions should be developed and implemented urgently. This paper shows the fea-sibility of the seismic isolation solution on a typical case study. Seismic vulnerability of an existing industrial steel silo system has been investigated, and a retrofitting solution has been proposed making use of the curved surface single sliding pendulum devices. Incremental dynamic analysis method has been used to compare the performance of the original and the retrofitted solutions. Structural benefits of the seismic isolation solution have been quantified in terms of inelastic deformations, base shear, inter-story drifts and isolator displacements. The seismic behaviour of the original and the retrofitted structure has been compared by means of fragility curves.
\end{abstract}

\section{Introduction}

Storage elements employ a predominant part (over 90\% of the total surface) of the industrial plants. Silos are the industrial storage components that are used for storing a huge range of different solids and liquids such as grain, cereals, chemical agents [1]. Generally, these structures are made of steel, and they can be both lying on a foundation (anchored or unanchored ground supported silos and tanks), or elevated (supported by a structural frame) as shown in Fig. 1 [2]. Their shapes can be complex because of the vent, lifting and ensilage systems, and several technical details such as conveyor belt, cochlea, symmetrical or unsymmetrical hopper.

Silos are special structures that are subjected to several loading conditions, which may collapse in unusual modes. They have been considered as "non-building structures" [4], and the main attention has been so far paid on their functionality under service conditions. Their structural components have not been under focus for accidental loads such as earthquakes. The seismic behaviour of

\footnotetext{
* Corresponding author at: Department of Architecture, Built Environment and Construction Engineering, Politecnico di Milano, Italy.

E-mail address: alper.kanyilmaz@polimi.it (A. Kanyilmaz).
}

these structures is very complex and not well assessed so far. Yet, their damage or collapse can have very devastating direct (the loss of the container and of the stored material, or its contamination) or in-direct (relative replacement costs, clean-up and possible environmental damage, injury or loss of life) consequences [5]. To guarantee human life safety and optimize the use of resources, the effort spent for the evaluation of seismic risk for the existing buildings and mitigation strategies for its reduction [6], should be extended also to the industrial systems.

In ground-anchored storage systems with liquid content, earthquake loading generates an extra horizontal pressure on the silo wall, which is also influenced by the material characteristics of the content. These conventional liquid storage tanks have been studied numerically and experimentally by several researchers, to understand their seismic behaviour. Housner [7] proposed an analytical model simulating the liquid mass portion moving with the tank as an "impulsive" mass, and the sloshing effect on the surface by "convective" mass. Based on this research, several researchers have studied various aspects such as flexibility and the effect of axial forces on the tank wall, and the code parameters [8$10]$. On the other hand, concerning the elevated silos with granular content, the entire structure and its contents behave like an inverted pendulum with a very large supported mass and the 


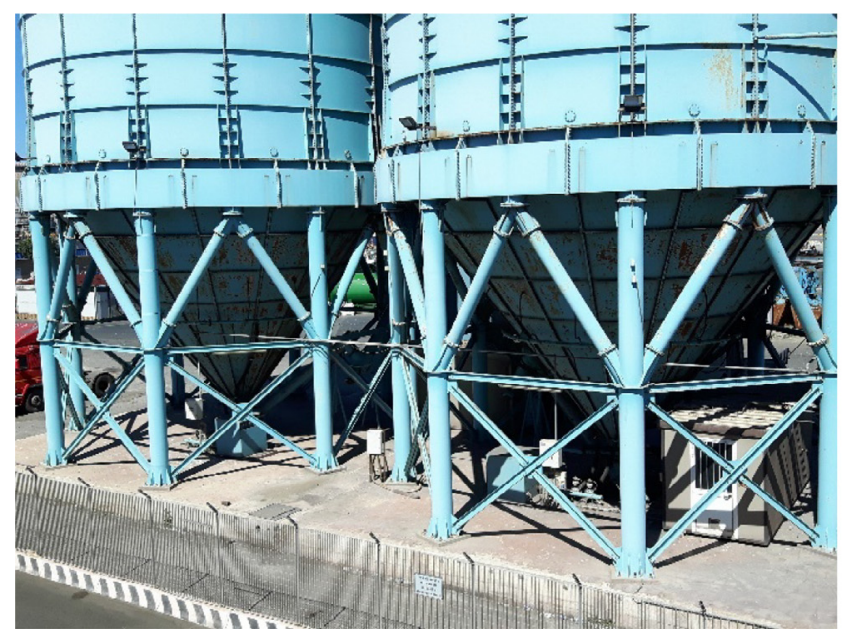

a. Elevated silos, Porto di Piombino, Italy

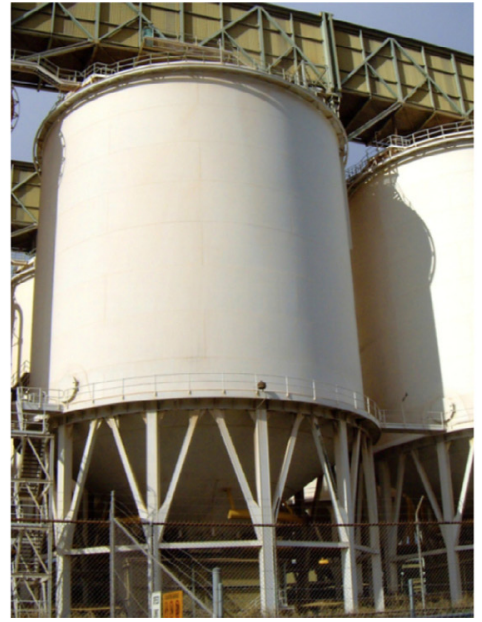

b. 10,000 ton steel grain storage, Australia [2]

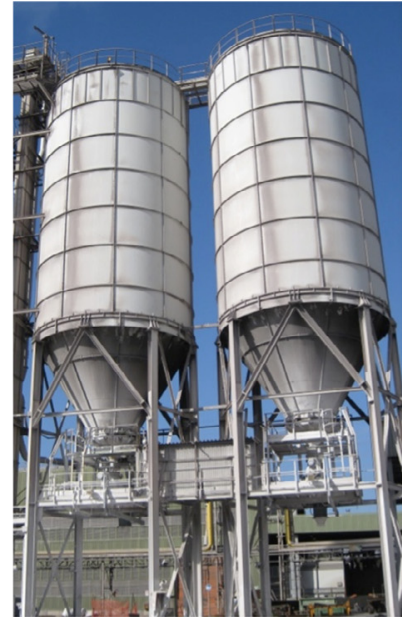

c. SOC silos (ILVA) [3]

Fig. 1. Elevated silo examples.

weaker component under seismic action is usually the supporting frame. As the silo height increases, the height of the mass center also increases and the moment arm for the lateral load with corresponding overturning moment at the base rapidly rises. In this case, the behaviour of the stored material, and its properties, are usually less significant than in ground supported silos. Several modelling philosophies for the elevated silos have been compared in another paper [11], where it was concluded that concentrated mass approach provides sufficient degree of reliability to model elevated silos filled with granular content. Such approach has been also validated by several other researchers [12,13]. A more sophisticated method taking account of the interaction between silo wall and content would have a very large number of degrees of freedom, for which implementing an incremental dynamic analysis with several hundreds of accelerograms would not be feasible in terms of computational time and storage of the output data. Therefore, in this paper, the focus has been given on the seismic performance of supporting steel structure of the silo-group systems, which represents the main cause of their global collapse.

In many cases, the existing silos in the earthquake-prone areas have been constructed before the latest updates of the seismic design codes $[3,11]$, hence their current seismic reliability is very low. After 2001 El Salvador earthquake, there were three causalities due to a silo collapse. After 1987 Edgecumbe (NZ) earthquake, steel milk silos collapsed, and thousands of liters of milk were lost. 1999 Chi-Chi Taiwan Earthquake caused collapse of silo because of the bottom segment and foundation anchorage, leaving the silo body without much damage [5]. After 7.2 magnitude Van (Turkey) earthquake in 2011, many industrial facilities with a lot of silos were seriously damaged, which caused a huge economic loss to the small and medium size companies because of both content and structure losses (Fig. 2). Almost all elevated cement and wheat silos were fully collapsed or seriously damaged during this earth-quake [14]. After this event, main collapse modes were due to the rupture at the base due to excessive bending and bearing stres-ses, local buckling and anchorage failures, and welded connection failure $[14,15]$. These damages from the recent earthquakes high-light the vulnerability of elevated silos and the substantial need to find efficient retrofitting solutions to avoid the future disasters.

In general, seismic retrofitting of structures can be done in two ways: i) strengthening the structural elements to increase seismic resistance of the structure ii) using seismic isolation or dissipation devices to decouple the superstructure from the ground shaking effects. The first method is the traditional one, which requires often long construction schedules, and usually partial or full demolition and reconstruction that often leads to costly operations [16]. The second one has become quite popular and efficient in the mitigation of seismic effects on the building structures. Many successful applications have been reported [17-26], and their functionality has been validated under recent earthquake events $[27,28]$.

Worldwide building codes mainly focus on civil structures. For industrial systems, the focus is given for the design of new structures, rather than the seismic rehabilitation of the existing ones. Isolation and dissipation devices have been largely investigated for civil structures, but there are not any specific indications for the application of these devices in the industrial systems. Some research has been done to study the effectiveness of the seismic isolation devices for the protection of ground-anchored tanks [2932]. Elevated silos are treated in EN 1998-4-2006 "Silos, tanks and pipelines" [33], but without any provisions regarding seismic isolation.

Seismic protection of silos may be efficiently provided by the isolation devices. These devices reduce the seismic accelerations suffered by structures, shifting the first mode frequency to a lowenergy range in the response spectrum [3,34] (Fig. 3). In this way, structure above the isolators does not get any damage from the earthquake, and its functionality is not interrupted for repair purposes [34]. After the earthquake, inspections and possible replacements are limited to the isolation devices, and not the bearing structure of the silos.

The European Research project PROINDUSTRY (Seismic Protection of Industrial Plants By Enhanced Steel Based Systems) aimed to develop innovative seismic protection systems, both for the design of new industrial plants and for the retrofit of existing ones, based on seismic isolation and energy dissipation techniques $[3,12,13,35,36]$. This paper presents the efficiency of curved surface sliders for an elevated silo structure studied in the PROINDUSTRY project. An existing elevated silo group located in Italy is selected as a case study. Its three-dimensional model has been developed using nonlinear plate elements for silos, and fiber-based distributed plasticity beam elements for structural components (all beams, columns and bracings). A total of 297 nonlinear dynamic time-history analyses have been performed, incremental dynamic analysis (IDA) [37] curves have been plotted for low-to-moderate 


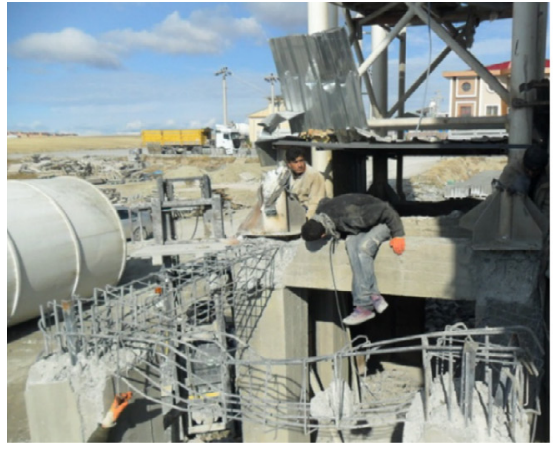

a. Supporting concrete failure [14]

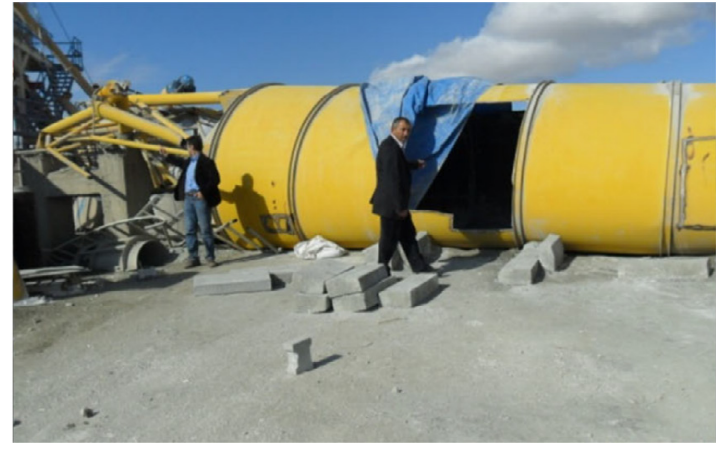

b. Collapse due to brittle welded connection failure [14]

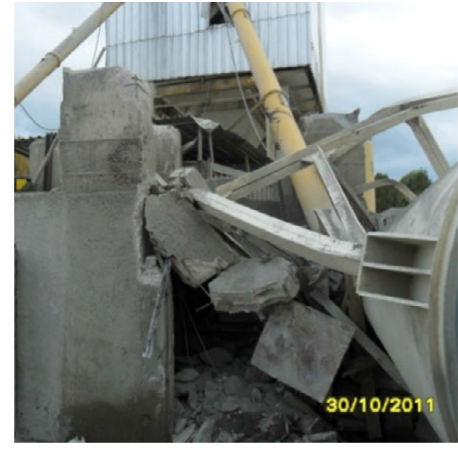

c. Local buckling and anchorage failure [14]

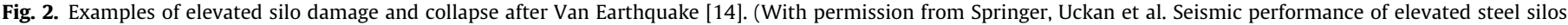
during Van earthquake, October 23, 2011. Nat Hazards, Figs. 4, 7 and 9).

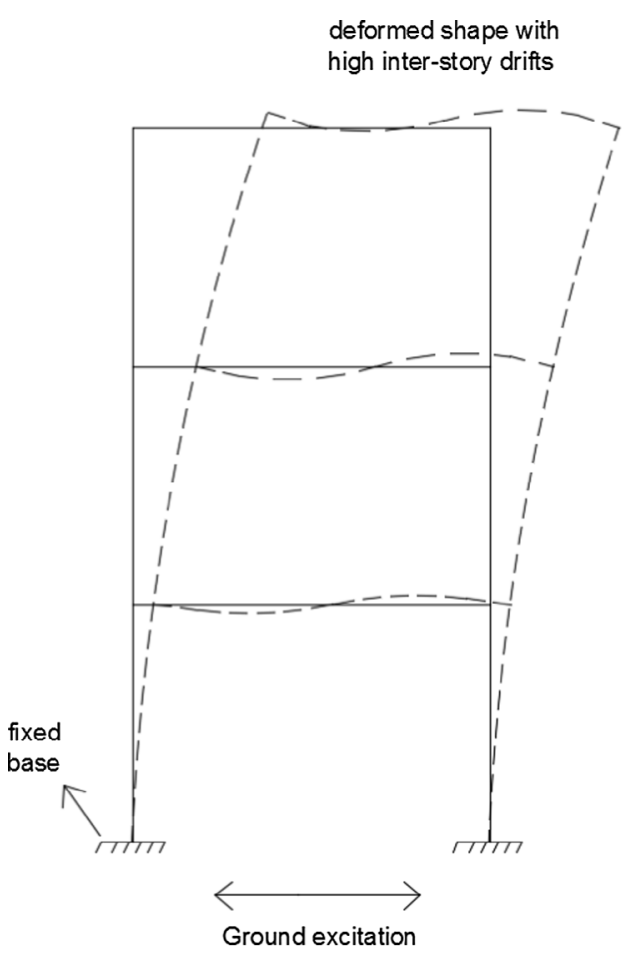

a. Fixed base structure

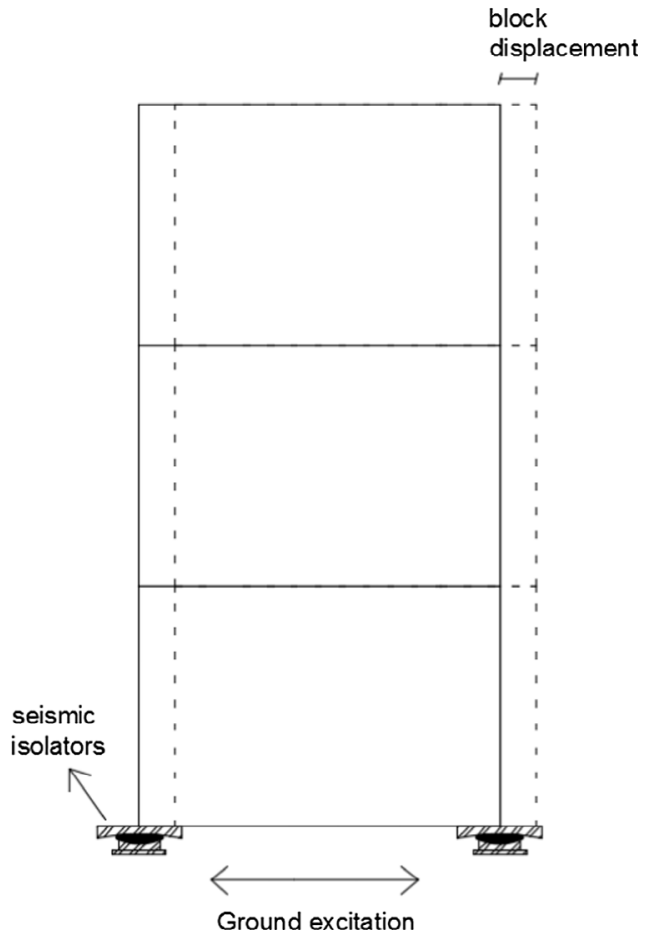

b. Base isolated structure

Fig. 3. Schematic behaviour of a non-isolated and of a base isolated structure.

and high seismicity actions. Performance of the structure before and after retrofitting has been reported by means of inelastic deformations, base shear, inter-story drifts, isolator displacements, and residual inter-story drifts. To represent the level of structural damage as a function of the ground motion intensity, fragility curves have been plotted for both cases.

\section{Case study}

The benchmark case study is an elevated silo group, inside the large industrial complex of SOLVAY site at Rosignano (in the province of Livorno - Italy) (Fig. 4). The silos, designed and built towards the end of the $80 \mathrm{~s}$, are currently used as storage for chemical material sodium percarbonate with a density of $1200 \mathrm{~kg} / \mathrm{m}^{3}$. The silo group consists of 3 steel silos, each one with an outside diameter of $3.5 \mathrm{~m}$. The wall thickness changes from $12 \mathrm{~mm}$ to
$8 \mathrm{~mm}$ along the silo height of $13.35 \mathrm{~m}$. The silo sub-structure is made of Fe360 steel with E $=210,000 \mathrm{MPa}$ and density of $7850 \mathrm{~kg} /$ $\mathrm{m}^{3}$. This benchmark represents a typical silo group widely used in industry. Moreover, its asymmetric structural plan requires a more challenging retrofitting design.

The geometry of the structure and the materials are known thanks to the design drawings received in the context of the research project PROINDUSTRY from the archive of the project partner Solvay [3]. Fig. 5 shows the front and side views of the structure, where another 2-silo group can be noted. This study focuses on the group of 3-silos, disregarding the adjacent silo group, for the sake of simplicity.

The substructure consists of a steel frame composed of 6 columns on 2 levels for a total height of 8,94 meters. The second structural level on one side $(\mathrm{y}=+0 \mathrm{~mm})$ has a concentric X-bracing with UPN200 profiles connected in the mid-section 


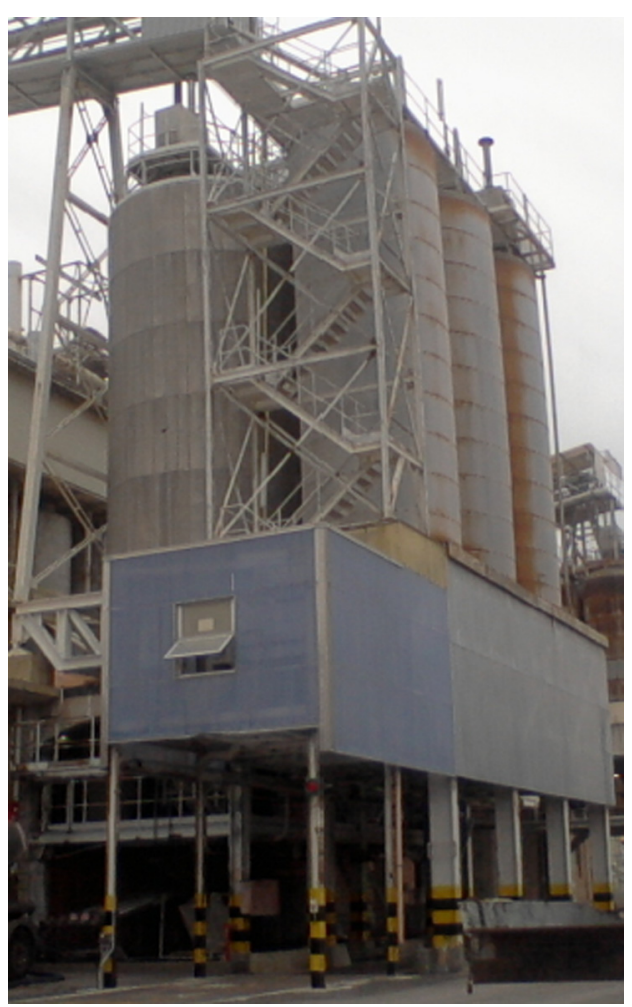

Fig. 4. Case study.
(Fig. 6.a, Fig. 7.a), on the other side $(\mathrm{y}=+4000 \mathrm{~mm})$ a chevron $(\mathrm{V})$ bracing with HE240B profiles placed between the two columns (Fig. 6.b, Fig. 7.b). Horizontal planes are shown in Fig. 8 and Fig. 9.The braces are connected to the beam-to-column joints with bolted connections, while all the beam-to-beam connections and beamto-column joints have been made with flanged end plates.

The silos are connected to the steel sub-structure by means of stiffener plates (Fig. 10). 24 stiffener plates are welded to the silo wall, equally spaced around its perimeter. These stiffener plates are then welded to the ring beam with $150 \times 30 \mathrm{~mm}$ cross section. The ring beam is bolted to the support structure beams.

\subsection{Numerical model - original structure}

Three dimensional behaviour of an elevated silo can be quite complicated, and the best way to simulate it would be by means of 3D solid finite elements making use of the convective and impulsive mass components as developed by Housner [7]. In this paper, since the most vulnerable component is expected to be the supporting structure of the elevated silo, a simplified approach has been used, where the silo wall elements have been modelled by plate elements and the steel profiles have been modelled by beam elements. The granular content of the silo has been assumed to have no sloshing effects, therefore, a spring mass model has been developed simulating only the impulsive component.

To study the simplified global nonlinear response of structures, most common alternatives are the concentrated plasticity and fiber-based modelling approaches. Concentrated plasticity approach limits the inelastic deformations in the individual parts

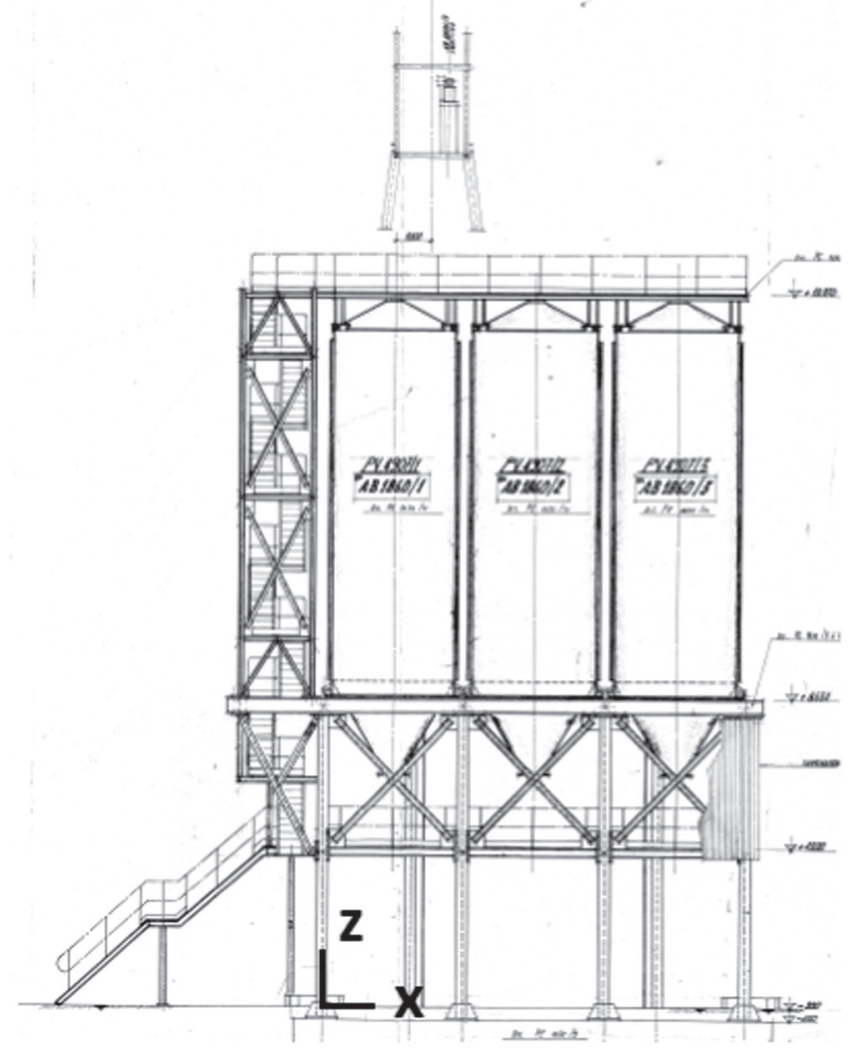

a. Front view

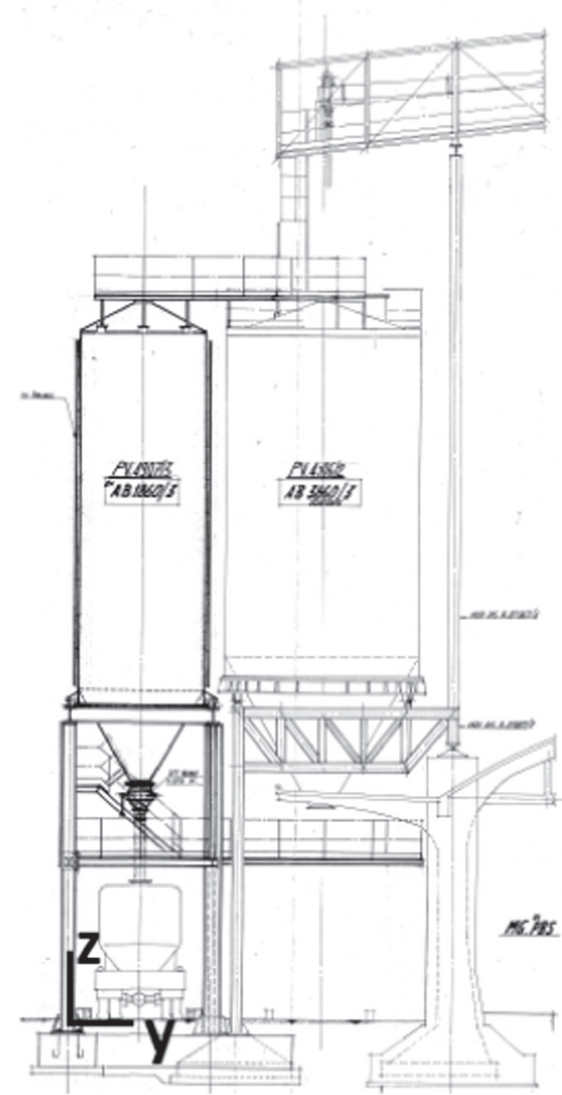

b. Side view

Fig. 5. Front and side views of the case study - original drawings. 


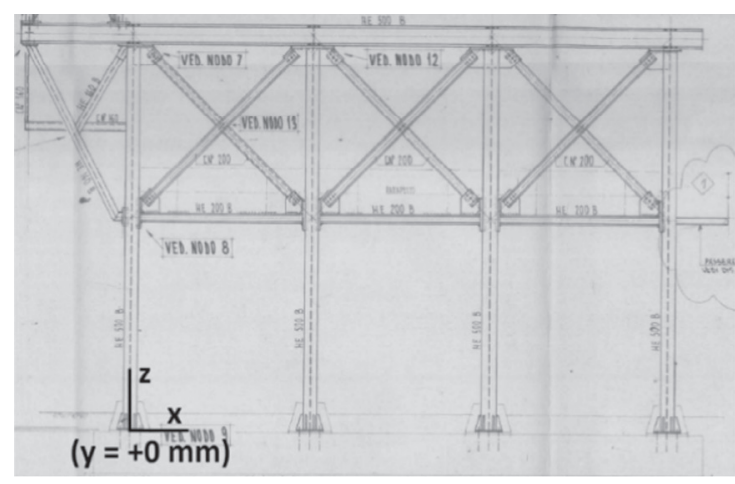

a. $y=+0 \mathrm{~mm}$

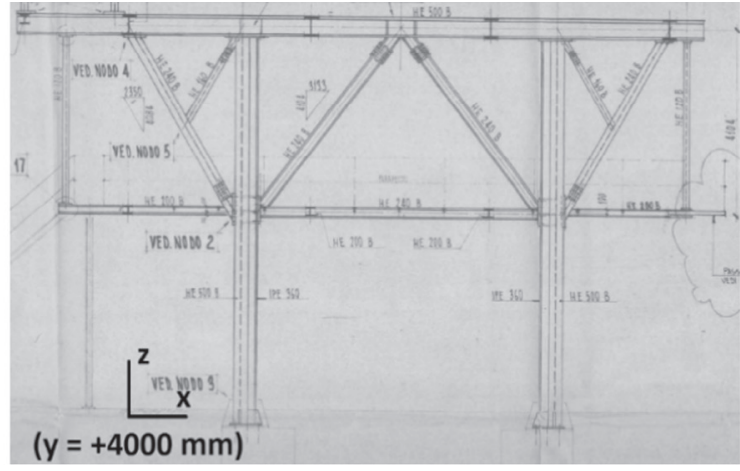

b. $y=+4000 \mathrm{~mm}$

Fig. 6. Cross-sections - original drawings.

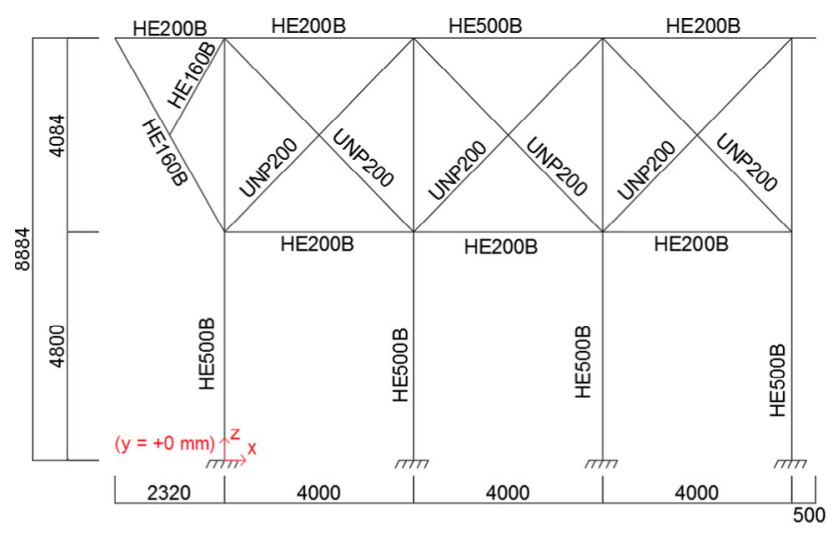

a. $y=+0 \mathrm{~mm}$

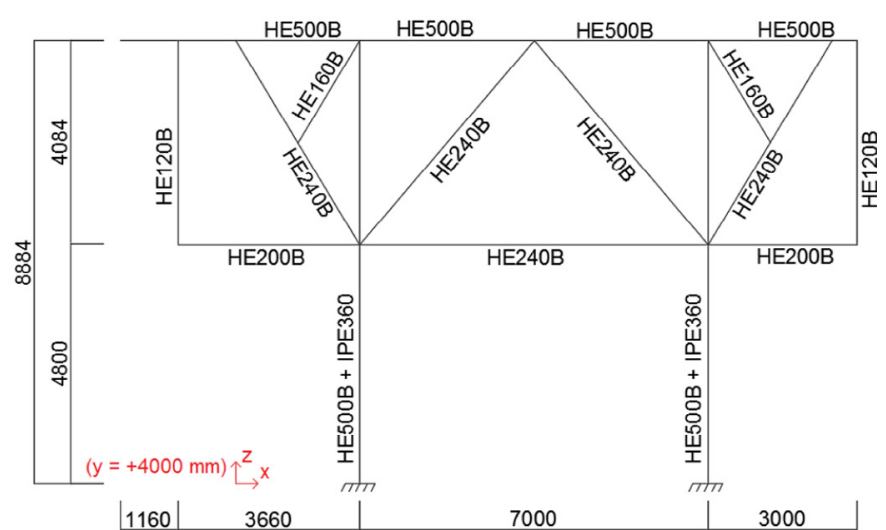

b. $y=+4000 \mathrm{~mm}$

Fig. 7. Steel profiles - Cross-sections.

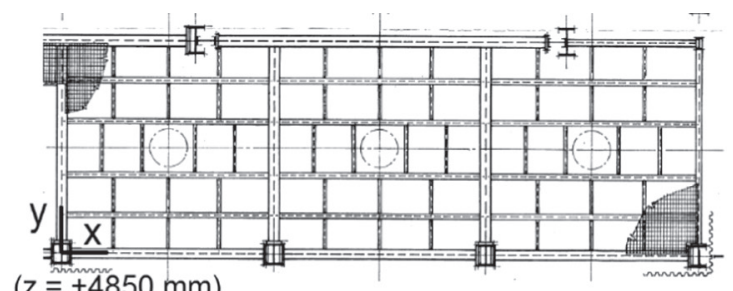

$(z=+4850 \mathrm{~mm})$

a. $z=+4850 \mathrm{~mm}$

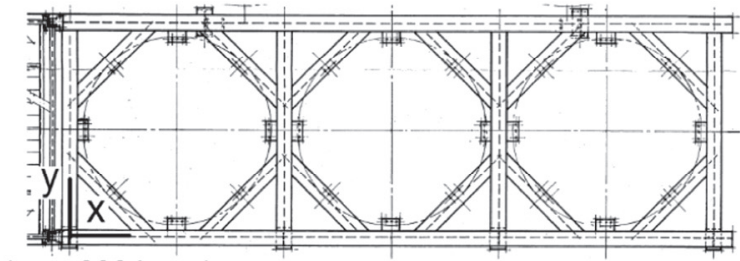

$(z=+8934$ mm $)$

Fig. 8. Structural plans - original drawings.

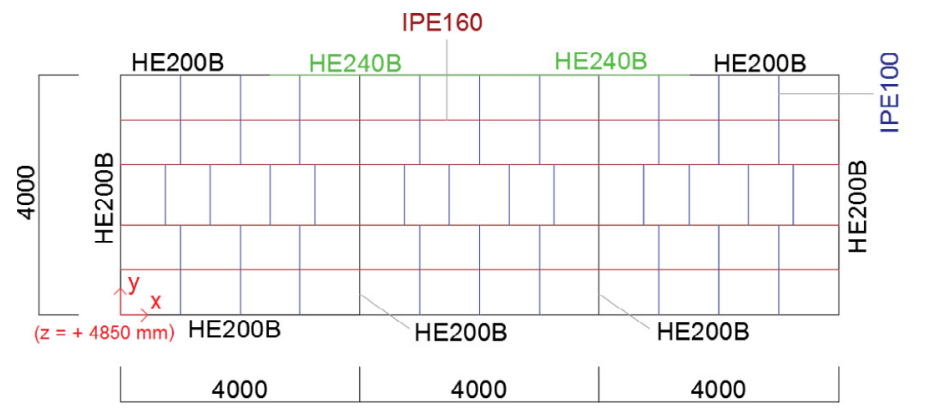

a. $z=+4850 \mathrm{~mm}$

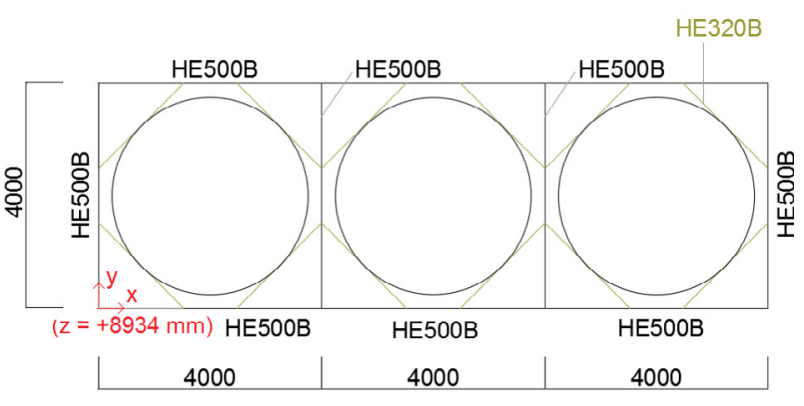

b. $z=+8934 \mathrm{~mm}$

Fig. 9. Steel profiles - Plans. 


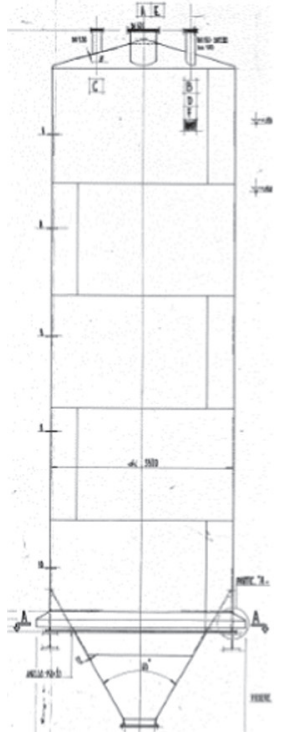

a. Silo in elevation

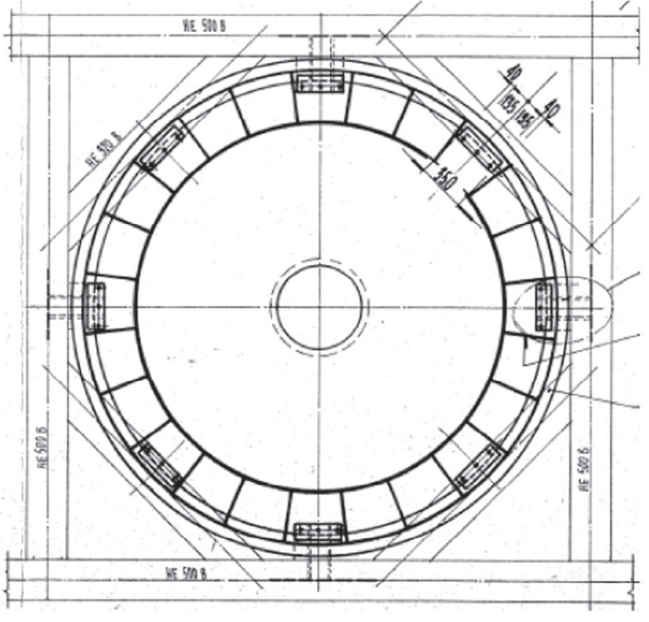

b. Ring beam - top view

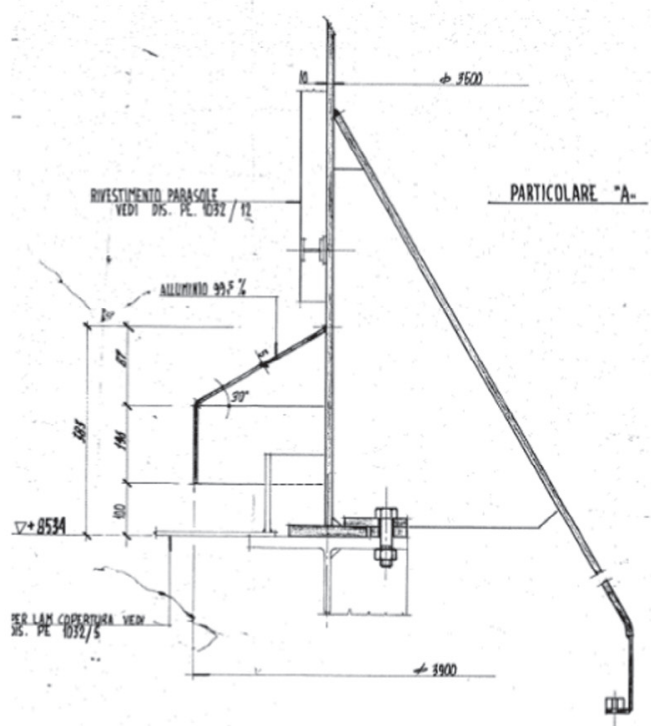

c. Stiffener plate

Fig. 10. Ring beam-silo connection detail - original drawings.

of the structural system (as plastic hinges) with the rest of the structure remaining elastic. Fiber-based modelling on the other hand, distributes plasticity by numerical integrations through the member cross sections and along the member length, and with a "plane sections remain plane" assumption [38-42]. Uniaxial material models are used to capture the nonlinear hysteretic axial stress-strain characteristics in the element cross sections. Fibers are numerically integrated over the cross section to monitor the axial force and moments, incremental moment-curvature and axial force-strain relations. The cross-section parameters are numerically integrated at several sections along the member length, using displacement or force interpolation functions. A possible configuration of the elastic-plastic response of a $\mathrm{H}$-section divided into fibers is shown in Fig. 11 [42].

Fiber-based modelling approach with distributed plasticity offers a good compromise in terms of accuracy and computational time to model hysteresis behaviour of steel struts $[43,44]$. Therefore, the beam elements in this study have been simulated using this approach, by means of Straus7 software [45]. Silo bodies, steel plate elements and rigid links that connect silo bodies and steel structure have been simulated by plate elements. Bracing elements are given initial imperfections according to EN 1993-1-1 [46]. Outof-plane initial imperfections have been applied at the mid-nodes of the elements, according to table 5.1 of EN1993-1-1 [46], considering buckling curve $c$ for UPN cross-section (Fig. 12.a.). To activate initial imperfections in the nonlinear analysis, first a linear static analysis has been run. The initial deformation of the frame at the first step of nonlinear dynamic analysis is shown in Fig. 12.b.

Connection between the silos and the steel frame has been modelled with plate elements (defined with a general membrane and bending thickness equal to the thickness of the silo wall), discretized by a mesh denser than the silo wall elements to have a more accurate solution within stress concentration zone. A view of the silo group and connection zone are shown in Fig. 13. The eccentric connection between silo and the steel frame has been modelled by means of a rigid link (Fig. 13.c)

The boundary conditions of column and beam elements have been defined according to the available connection detail drawings of the existing structure; the rotation degree of freedom of the bracings and the beams in the braced direction have been released, and the column bases have been considered fixed (restrained in all 6 degree of freedoms). The top of the silo has been modelled by means of rigid links, as shown in Fig. 14. The different modelling approaches described here have been validated and presented elsewhere [11].

In the analysis, the silos have been assumed to be completely full in order to simulate the case with the highest seismic mass. The total mass of 131 tons have been distributed at different levels along the height of silos by means of lumped masses connected to the silo wall by means of rigid links, as shown in Fig. 15.a. This

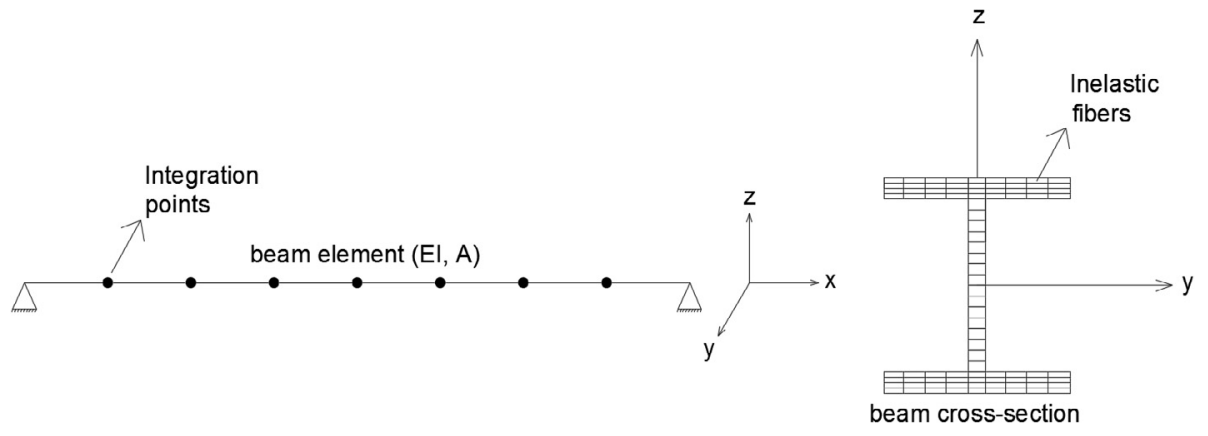

Fig. 11. Fiber based distributed plasticity model [42]. 


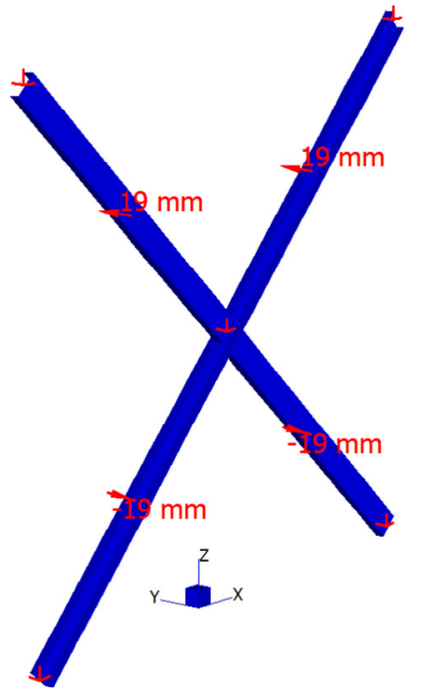

a. Initial imperfections applied at X-bracings

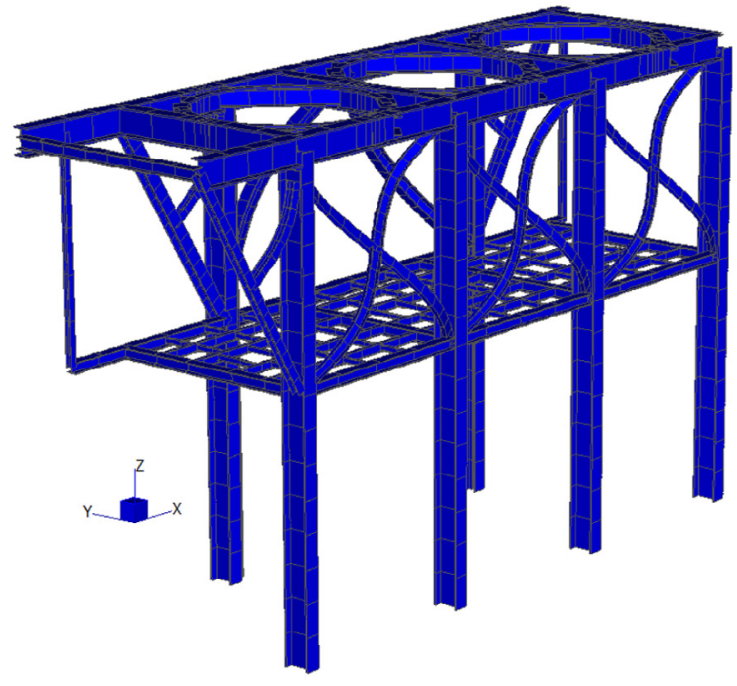

b. Deformed shape of the

structure with initial imperfections

Fig. 12. Application of initial imperfections.

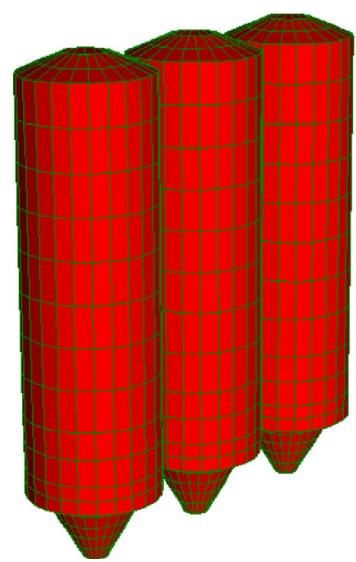

a. Silos modeled by plate elements

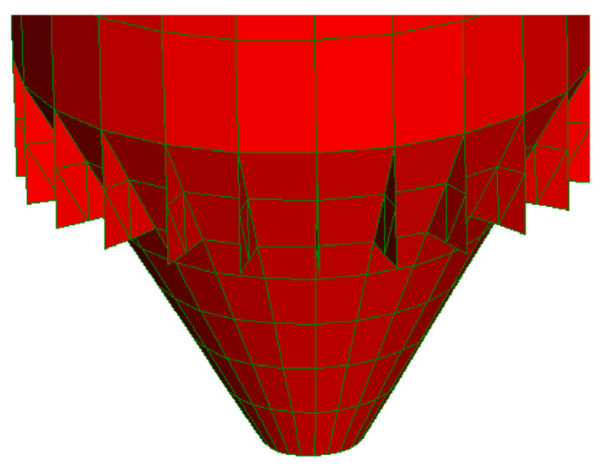

b. Connecting plates between silos and the steel frame

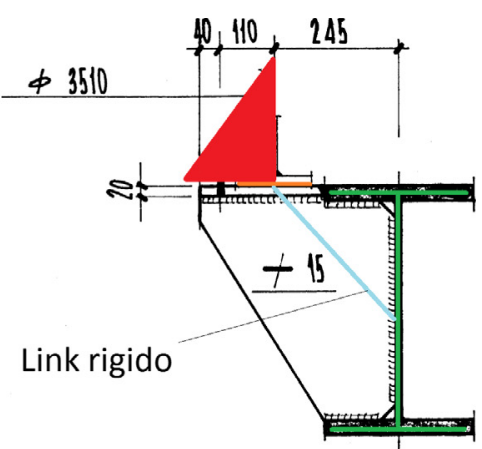

c. Rigid link connection

Fig. 13. Model of silos.

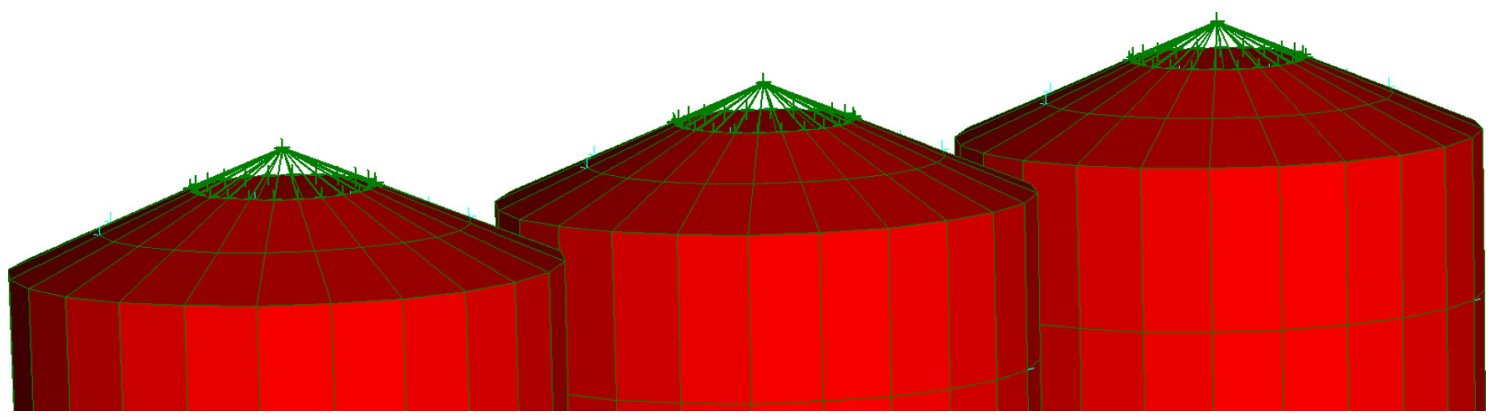

Fig. 14. Rigid links at the silo top.

lumped mass model for the silos containing granular material has been validated in another paper, where comparisons have been made between a complex modelling approach using three dimensional soil type brick elements, and a simplified approach in which ensiled material has been simulated by means of distributed masses [11]. Calculated masses of silo content have been shown in Table 1. In addition to these masses, the software adds the self-weight of the silo wall (10 tons/silo) and structural steel elements (31 tons)

$M_{\text {silo }}=H W+S C 10+S C 8+U S=131 t$ 


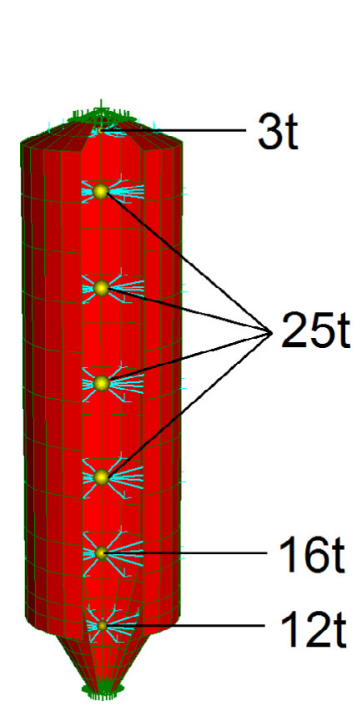

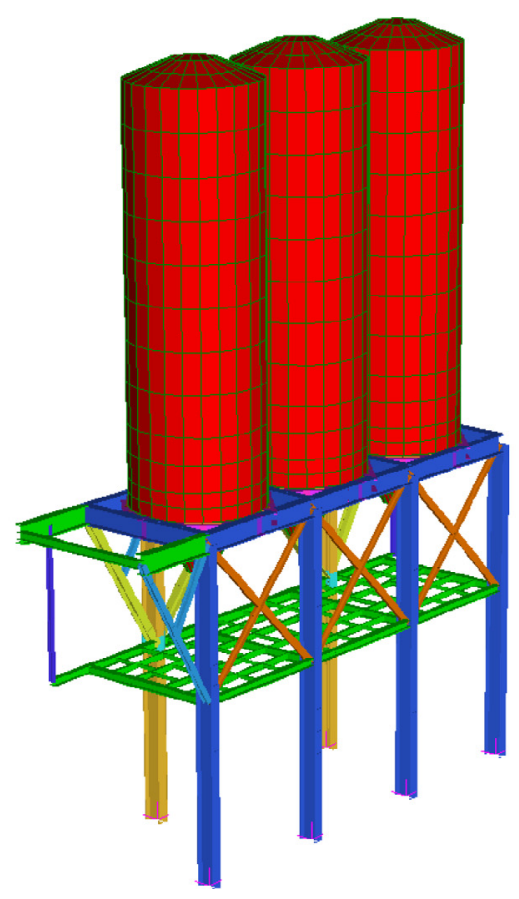

b. X-bracing side

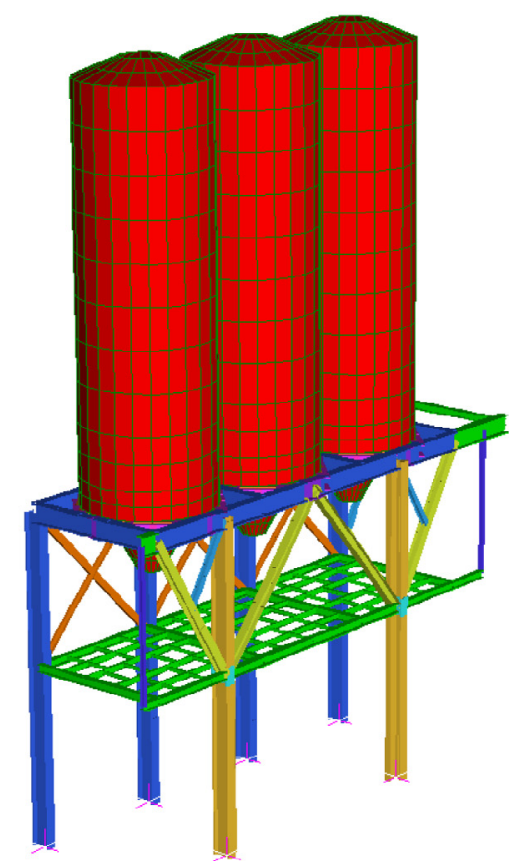

c. V-bracing side a. Lumped masses

Fig. 15. Numerical Model (original structure).

Table 1

Mass values.

\begin{tabular}{ll}
\hline Component & Mass (tons) \\
\hline Hopper weight (HW) & 12 \\
Silo content within 10 mm wall thickness (SC10) & 16 \\
Silo content within 8 mm wall thickness (SC8) & 100 \\
Upper part of silo (US) & 3
\end{tabular}

\section{$M_{\text {total }}=3 * M_{\text {silo }}+$ Self weight of steel $=454$ tons}

In order to explore the situation of the existing structure at fully-loaded condition, a static analysis has been performed only under gravity loads. From Fig. 16 it can be observed that at this condition, beam fiber and plate stress values are below the material yield limit.

From the gravity loading analysis, the base reactions have been obtained at each node (Fig. 17). This information will be needed for the design of the seismic isolation system at the retrofitting case.

The results of the modal analysis are reported in Table 2. From Fig. 18 it can be observed that in the second fundamental mode that is supposed to be a longitudinal one, there is also a global torsional component, which is the result of the asymmetric structural plan of silo group.

To achieve ground motion variability, the structure has been analyzed before and after retrofitting, under two sets of 11 spectracompatible natural time-acceleration history inputs. The first set is characterized by low-to-moderate seismicity (Table 3 ), while the second set is characterized by high seismicity (Table 4). The hazard curves have been estimated within the PROINDUSTRY project $[3,36]$ according to the Italian Building Code [48].

For each group of accelerograms, 9 scale factors (SF) have been defined, which are associated with peak ground acceleration values of annual probability of exceedance. Scaled $\mathrm{a}_{\mathrm{g}}$ values are reported in Table 5 and Table 6 for low-to-moderate and high seismicity data [36]. Probability curves for both sets are shown in Fig. 19.

\subsection{IDA results - original structure}

In the original structure, even in the analysis with low scale factors, yielding took place at the column bases. When the acceleration intensity has been increased, the inelastic deformations have expanded also to the column ends, bracings, and to the connections between silo and supporting structure (Fig. 20).

Fig. 21 shows that the numerically obtained failure mechanisms represent common structural damages that can be observed after strong earthquakes, such as Van Earthquake [14]: high stress concentrations in the silo-structure connections, inelastic deformations at the column bases and at the first level column ends which induces soft story collapse mechanism, and yielding at the bracings. Therefore, the seismic retrofitting solution should address these criticalities.

The seismic vulnerability assessment of the structure has been made by means of incremental dynamic analysis (IDA) as an efficient seismic assessment tool widely used in the field $[12,13,37,49,50]$. The global capacity curves of the structure have been plotted in terms of peak ground acceleration (PGA) and three response parameters (top displacement, inter-story drift ratio and base shear). Plotted from the structure's elastic state until the global collapse, the capacity curves provided both qualitative and quantitative insights for the nonlinear response of the structure and its dynamic capacity for a range of selected natural ground motion data. Using this data, fragility curves have been plotted according to the damage states defined for different inter-story drift levels, which showed the probability of reaching a defined limit state as a function of the peak ground acceleration.

From all the analyses, base shear, displacement and inter-story drift response parameters have been obtained, and IDA curves have ben plotted. Results of the IDA analysis based on high and low-tomoderate seismicity accelerograms are shown between Fig. 22 and Fig. 25. For peak displacements (Fig. 23), the control node is taken as the center of gravity of whole system. Global nonlinear behaviour caused by inelastic deformation in the structural elements 


60,00
53,68
41,05
28,42
15,79
3,16
$-9,47$
$-22,11$
$-34,74$
$-47,37$
$-60,00$

Plate Stress:VM Mid plane (MPa)

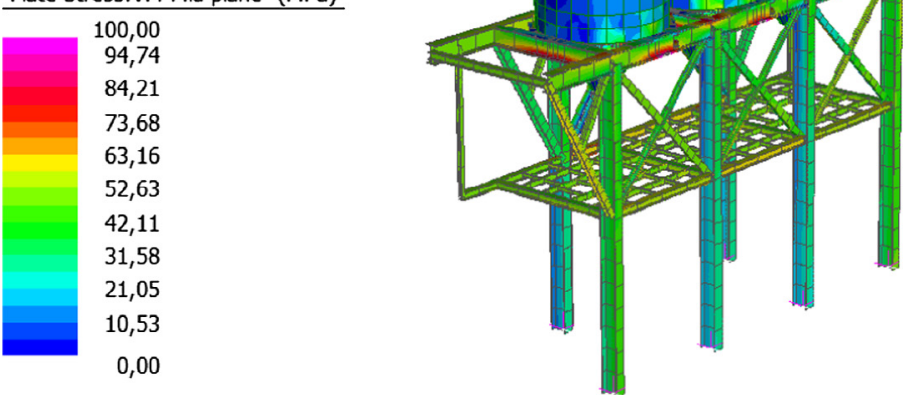

a. Stresses X-bracing side

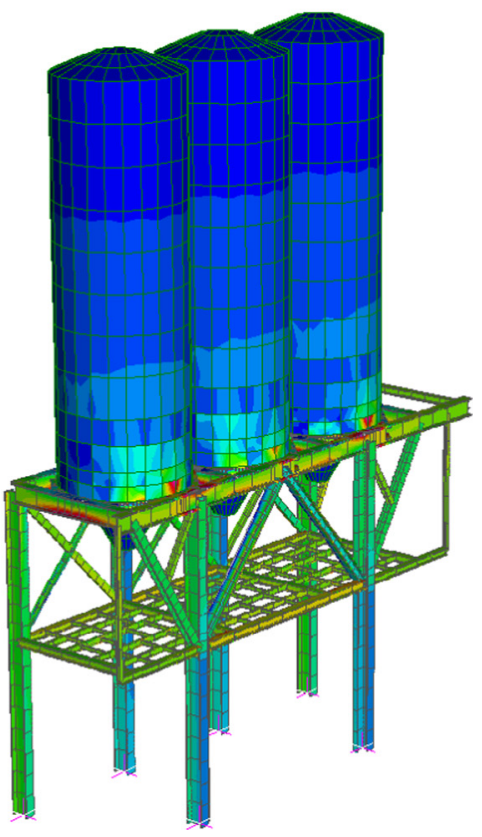

b. Stresses V-bracing side

Fig. 16. Stresses at the structure under gravity loads (original structure).

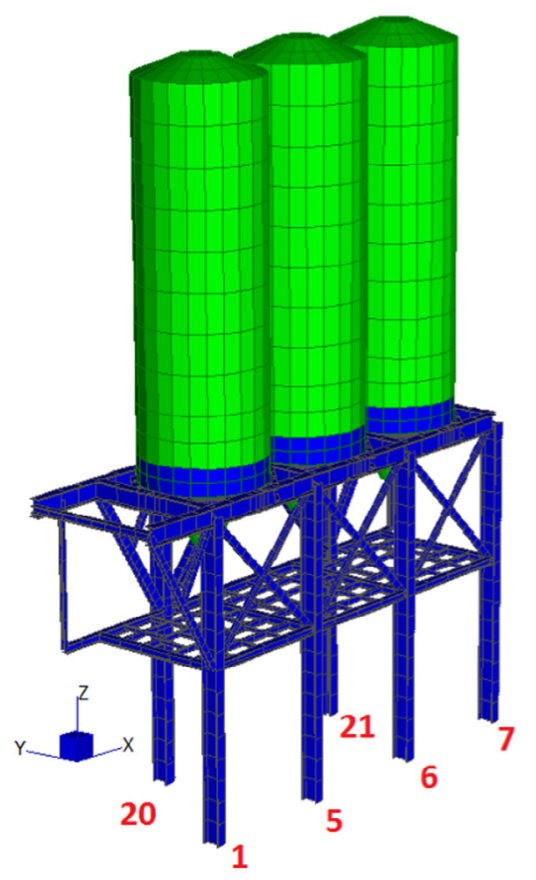

a. Base node numbers

\begin{tabular}{cc}
\hline Node & $F_{z}[k N]$ \\
\hline 1 & 358,3 \\
5 & 777,8 \\
6 & 798,8 \\
7 & 340,2 \\
20 & 1090,2 \\
21 & 1080,7 \\
\hline
\end{tabular}

b. Base reaction values

Fig. 17. Base reaction values under gravity loading (original structure).

Table 2

Modal analysis results (PF-X, PF-y, PF-Rz respectively represents translational X and Y and rotational $\mathrm{Z}$ mass participation).

\begin{tabular}{lllll}
\hline Mode & T [s] & PF-x (\%) & PF-y (\%) & PF-Rz (\%) \\
\hline 1 & 1,21 & 0 & 97.9 & 18.5 \\
2 & 1,05 & 90.2 & 0 & 0 \\
3 & 0,84 & 7.4 & 0 & 9.4 \\
\hline
\end{tabular}

is evident in high-seismicity diagrams. The base shear in the longitudinal direction $\mathrm{x}$ is in the range of $700-1100 \mathrm{kN}$. In the transverse direction $\mathrm{y}$, the recorded base shear values are much more dispersed among different accelerograms, and reach $1500 \mathrm{KN}$ (Fig. 24).

By plotting the base shear versus global displacement, the global seismic behaviour of the structure becomes more obvious. In both $\mathrm{x}$ and $\mathrm{y}$ directions, elasto-plastic behaviour of the capacity curve is evident. High inter-story drifts (IDR) are evident at the first floor (Fig. 25), which indicates a soft-story collapse risk. 


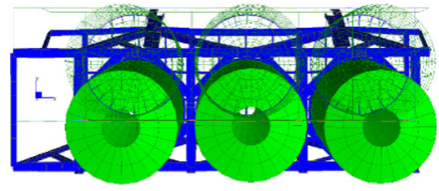

a. $1^{\text {st }}$ mode

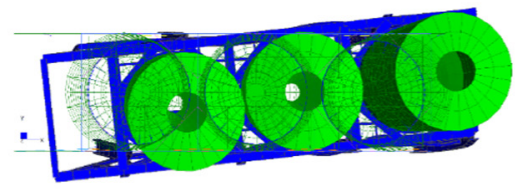

b. $2^{\text {nd }}$ mode

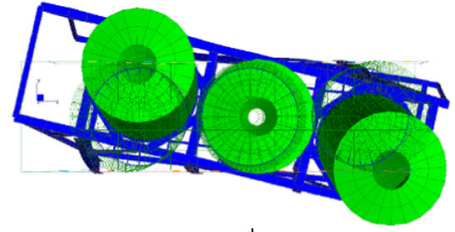

c. $3^{\text {rd }}$ mode

Fig. 18. First three fundamental modal shapes (original structure).

Table 3

Low-to-moderate seismicity earthquake data [36].

\begin{tabular}{llll}
\hline ID & Earthquake Name & Magnitude & Soil type \\
\hline ED147 & Friuli (aftershock) & 6 & $\mathrm{~B}$ \\
ED133 & Friuli (aftershock) & 6 & $\mathrm{C}$ \\
ED378 & Lazio Abruzzo & 5,9 & $\mathrm{C}$ \\
ED600 & Umbria Marche & 6 & $\mathrm{C}$ \\
ED181 & Tabas & 7,3 & $\mathrm{~B}$ \\
ED479 & Manjil & 7,4 & $\mathrm{C}$ \\
ED1911 & Komilion & 5,4 & $\mathrm{C}$ \\
ED4343 & Izmit & 7,6 & $\mathrm{C}$ \\
ED6978 & Izmit (aftershock) & 5,8 & $\mathrm{C}$ \\
IN318 & EMILIA_Pianura_Padana & 6 & $\mathrm{C}$ \\
IN381 & Christchurch & 5,3 & $\mathrm{C}$ \\
\hline
\end{tabular}

Table 4

High seismicity earthquake data [36].

\begin{tabular}{llll}
\hline ID & Earthquake Name & Magnitude & Soil type \\
\hline ED6349 & South Iceland (aftershock) & 6,4 & $\mathrm{~A}$ \\
ED196 & Montenegro & 6,9 & $\mathrm{~B}$ \\
ED535 & Erzincan & 6,6 & $\mathrm{~B}$ \\
ED74 & Gazli & 6,7 & $\mathrm{D}$ \\
ED1257 & Izmit & 7,6 & $\mathrm{C}$ \\
IN113 & South Iceland & 6,5 & $\mathrm{~A}$ \\
IN466 & Duzce & 7,1 & $\mathrm{C}$ \\
IN331 & Darfield & 7,1 & $\mathrm{C}$ \\
IN445 & Imperial Valley & 6,5 & $\mathrm{C}$ \\
IN451 & Loma Prieta & 6,9 & $\mathrm{~B}$ \\
IN461 & Northridge & 6,7 & $\mathrm{C}$ \\
\hline
\end{tabular}

Table 5

Low-to-moderate seismicity scale factors [36].

\begin{tabular}{llll}
\hline Return period (yrs) & $\mathrm{P}_{\mathrm{vr}}$ & $\mathrm{ag}(\mathrm{g})$ & Scale factor \\
\hline 2475 & $4 \%$ & 0199 & 2,78 \\
1950 & $5 \%$ & 01854 & 2,59 \\
949 & $10 \%$ & 01501 & 2,09 \\
402 & $22 \%$ & 0114 & 1,59 \\
280 & $30 \%$ & 01016 & 1,42 \\
202 & $39 \%$ & 00916 & 1,28 \\
144 & $50 \%$ & 00812 & 1,14 \\
101 & $63 \%$ & 00715 & 1,00 \\
60 & $81 \%$ & 00583 & 0,82 \\
\hline
\end{tabular}

Table 6

High seismicity scale factors [36].

\begin{tabular}{llll}
\hline Return period (yrs) & $\mathrm{P}_{\mathrm{vr}}$ & $\mathrm{ag}(\mathrm{g})$ & Scale factor \\
\hline 2475 & $4 \%$ & 0512 & 1,43 \\
1950 & $5 \%$ & 04687 & 1307 \\
949 & $10 \%$ & 03586 & 1,00 \\
402 & $22 \%$ & 02502 & 0698 \\
280 & $30 \%$ & 02122 & 0592 \\
202 & $39 \%$ & 01829 & 0,51 \\
144 & $50 \%$ & 01552 & 0433 \\
101 & $63 \%$ & 01292 & 0,36 \\
60 & $81 \%$ & 00987 & 0275
\end{tabular}

In the low-to-moderate seismicity context, the global behaviour of the structure remains mainly elastic, except for very high scale factors (Figs. 26-29). Therefore, seismic isolation device will be designed to considering only high-seismicity context.

\section{Retrofitted solution}

To retrofit the original structure, a single curved surface slider has been designed $[3,34]$. These devices mainly consist three main steel parts with inner sliding surfaces, where the internal part is spherical and allows rotations and horizontal sliding displacements. The devices have been placed between the column bases and the ground, with the objective of limiting the horizontal accelerations transmitted to the elevated silo group. Isolating the structure at the base was the most straight-forward solution from the constructional point of view (an investigation of another case study isolating it at the $1^{\text {st }}$ and $2^{\text {nd }}$ story to reduce the overturning moments on the isolators and to decrease the displacement demand is underway, and will be published in another paper). From the operational point of view, the creation of a rigid plane at the base may create problems for the free transit of truck under the silos. However, this problem can be solved, adopting a steel connecting platform placed just above the steel elements forming the rigid plane. Attention should be given to the proper design of gaps between the steel platform and the steel column or concrete foundations to avoid any obstacles to the free sliding of the isolated structure. Different from elastomeric isolators, the isolation period of the curved surface sliders is independent of the weight of the super-structure and depends only on the radius of curvature of the isolation device [51]. This can be an advantage for the elevated silo systems where the total weight is relatively low (with respect to the multi-story building systems). Besides, their re-centering capabilities are superior with respect to the other conventional isolation devices. In this study, single sliding pendulum isolator device has been chosen since it represents the most economic option among various curved surface slider devices. The obtained results can be extended to the systems with double or triple curved surface sliders, thanks to which the horizontal displacements of the isolated structure can be further reduced with increased device cost.

A static diagram of the forces acting in a single curved surface slider is shown in Fig. 30.a, while the force-displacement relationship is displayed in Fig. 30.b [51].

The equations governing the behaviour of the isolator are the following:

$$
\begin{aligned}
& \text { Response period of the Isolator } \quad T=2 \cdot \pi \cdot \sqrt{\frac{R}{g} \cong 2 \cdot \sqrt{R}} \\
& \text { Effective stiffness } \quad k_{\text {eff }}=\frac{W}{R}+\frac{\mu \cdot W}{D} \\
& \text { Effective response period } \quad T_{\text {eff }}=2 \cdot \pi \cdot \sqrt{\frac{R}{K_{\text {eff }} \cdot g}}
\end{aligned}
$$




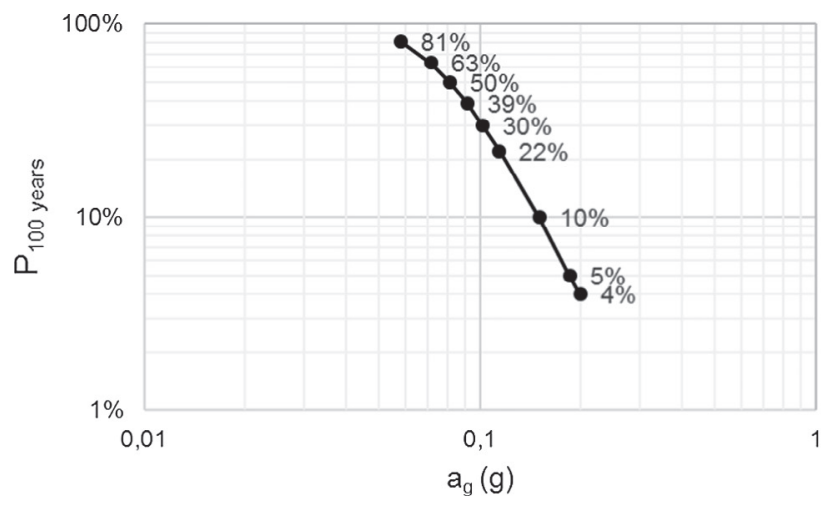

a. Low-to-moderate seismicity

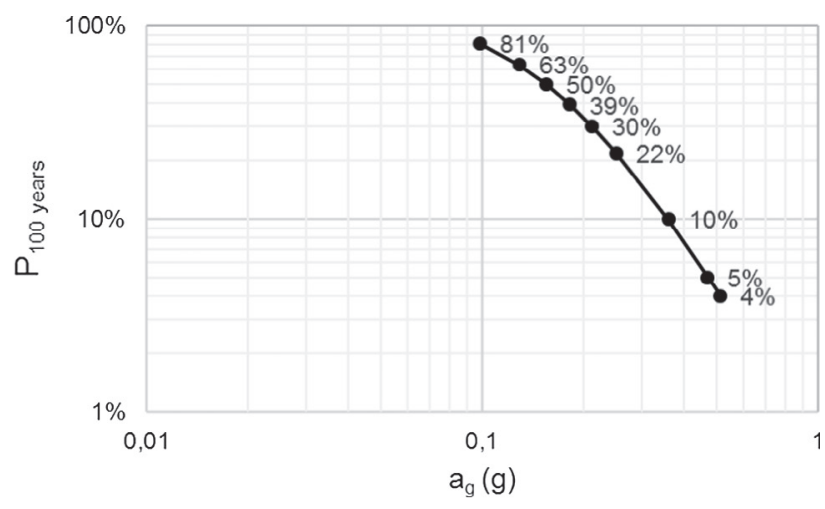

b. High seismicity

Fig. 19. Probability curves [36]
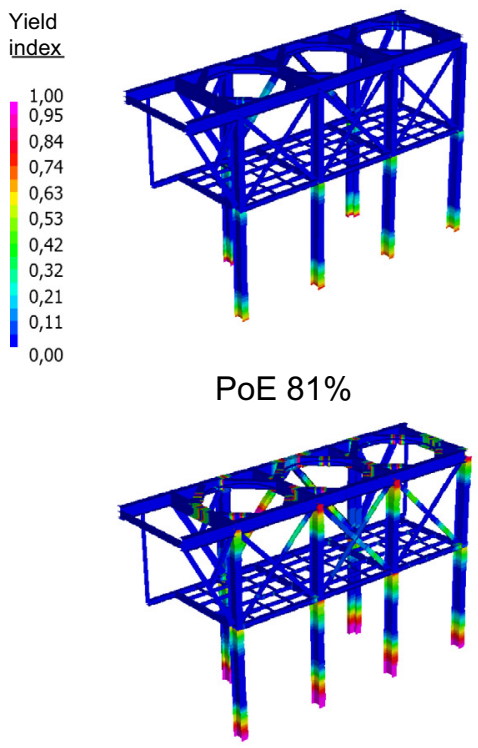

PoE $10 \%$

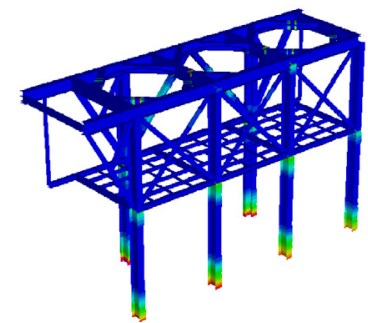

PoE 61\%

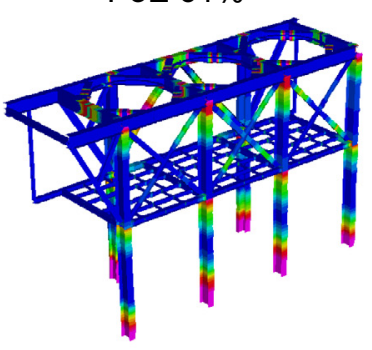

POE 5\%

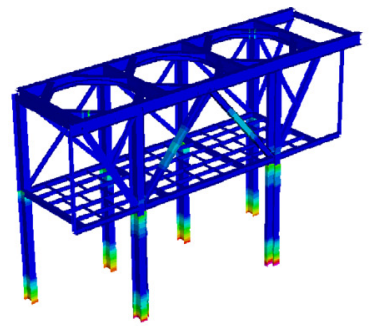

PoE $81 \%$

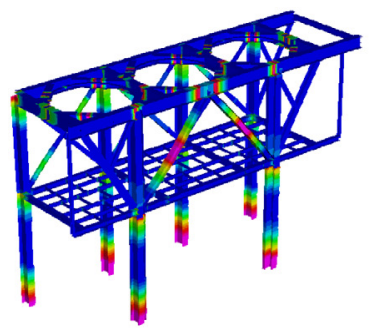

PoE $10 \%$

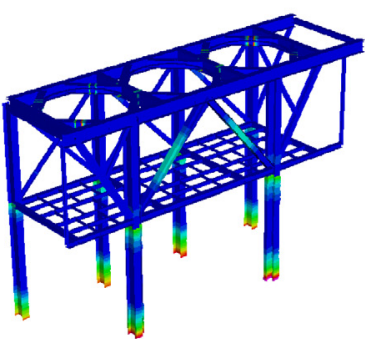

PoE 61\%

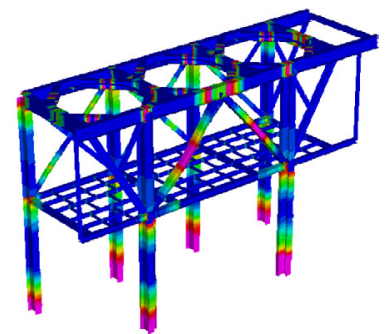

PoE 5\%

a. X-braced side

b. V-braced side

Fig. 20. Failure mechanisms of the original structure (record ED74).

Damping due to friction $\beta_{\text {eff }}=\frac{2}{\pi} \cdot \frac{\mu}{\frac{D}{R}+\mu}$

In these equations, $\mathrm{W}$ is the vertical load acting on the isolator agent, $\mathrm{F}$ is the horizontal force observed in the isolator, $\mu$ is the dynamic friction factor, $D$ is the expected maximum isolator displacement, $R$ is the radius of curvature and $\mathrm{T}$ is the isolation period. The friction coefficient $\mu$ is a function of the vertical pressure and the sliding velocity. Since the horizontal stiffness is related to the load acting on the isolators, in an optimal design a different isolator should be adopted for the design vertical load of each isolator.

\subsection{Numerical model - retrofitted structure}

The curved surface slider isolation device has been modelled by means of "contact" and "connection" elements of the Straus7 nonlinear FE package [45], acting in parallel. The contact element simulates the slip point by means of a friction coefficient and vertical stiffness, providing the compression stiffness immediately when its connection nodes come into full contact. Its elliptical yield surface ensures that the slip point is the same in all directions, and permits the simulation of the friction behaviour in all principal directions. Thanks to the plastic friction model incorporated in the contact element, when the direction of frictional motion changes, the frictional force reduces and changes sign as soon as the amount of reverse motion exceeds the small elastic forcedisplacement section of the contact element, which is related to the contact stiffness. In this way, frictional hysteresis can be simulated. On the other hand, the connection element provides the horizontal stiffness of the isolation device for a given weight and radius of curvature. The length of these elements does not have an influence on the isolator behaviour, therefore an approximate height has been defined to represent the isolator device dimensions, and they have been placed between the ground and the bottom column nodes as shown in Fig. 31.b. The model considers explicitly the uplift potential, which has been incorporated in the definition of the contact element (tension forces in the isolators are automatically released during the analysis). Therefore, the con- 


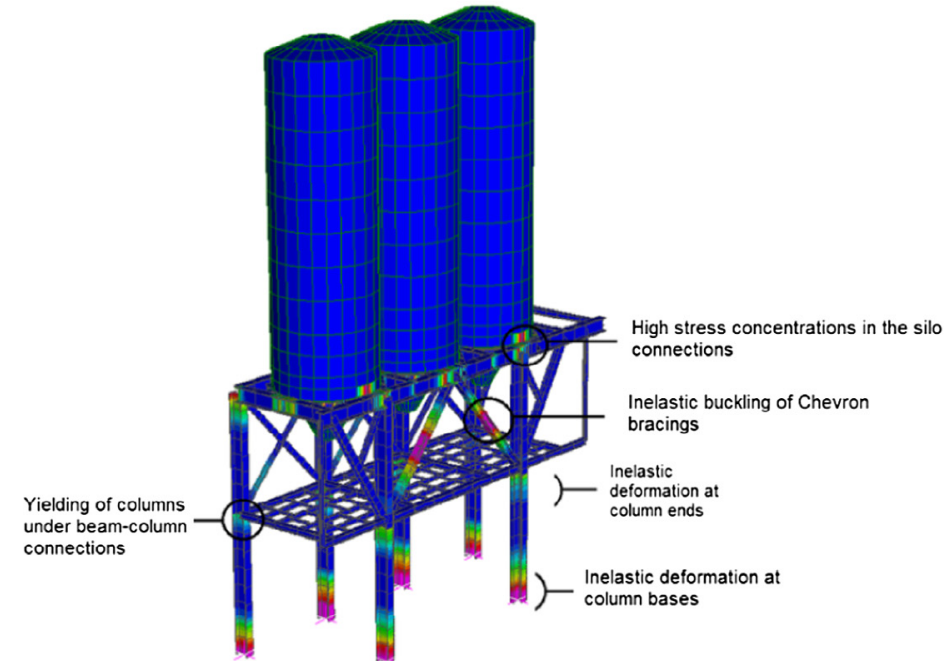

a. Failure mechanisms obtained from numerical analysis (ED74)
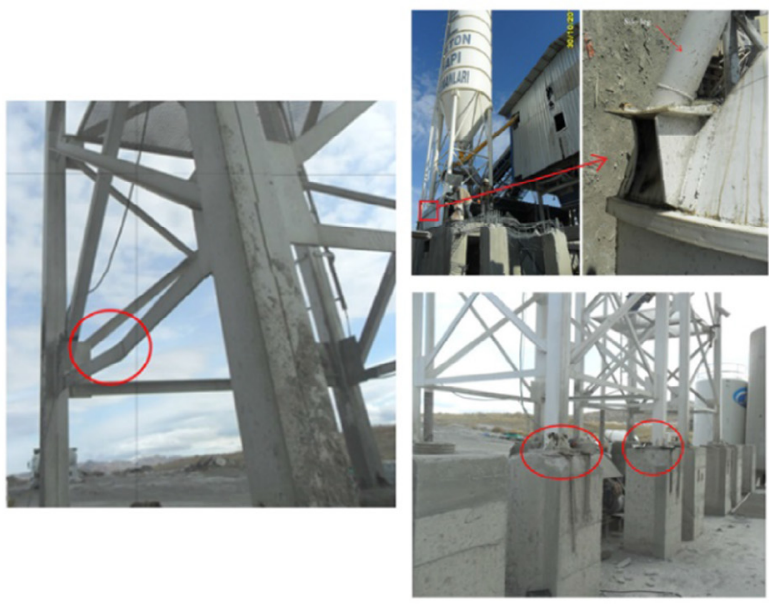

b. Example of damages observed on the structure [14]

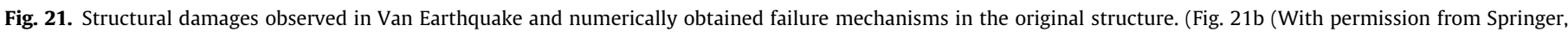
Uckan et al. Seismic performance of elevated steel silos during Van earthquake, October 23, 2011. Nat Hazards, Figs. 5 and 13)).

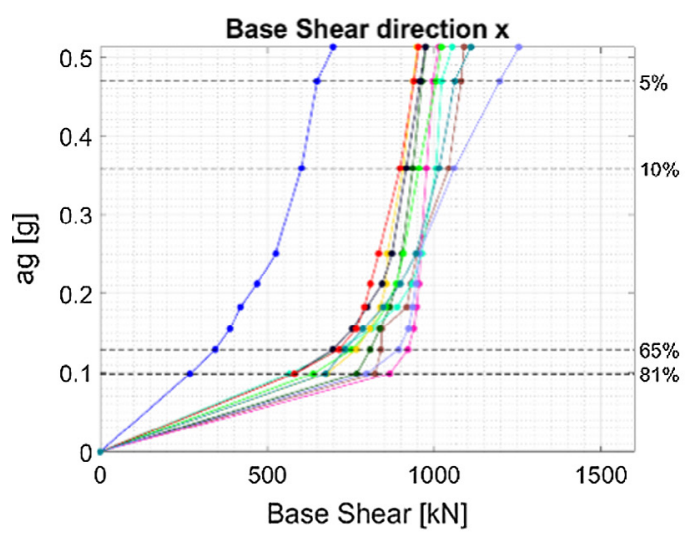

a. X-direction

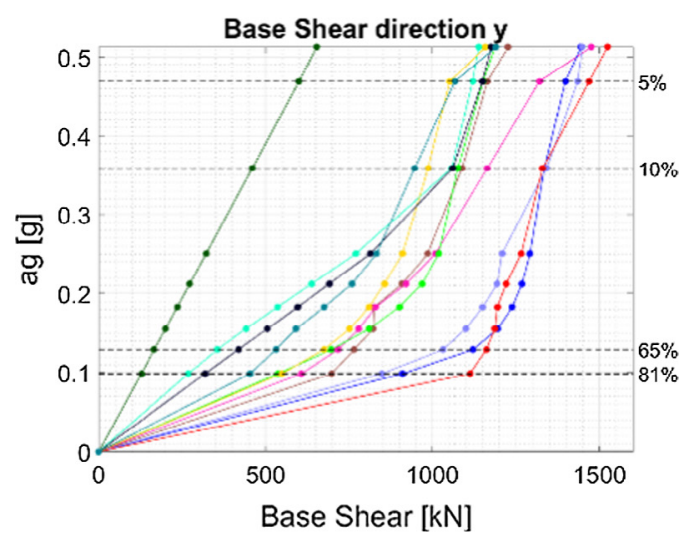

b. Y-direction

Fig. 22. Base shear vs $a_{g}(g)$ - high seismicity (original structure).

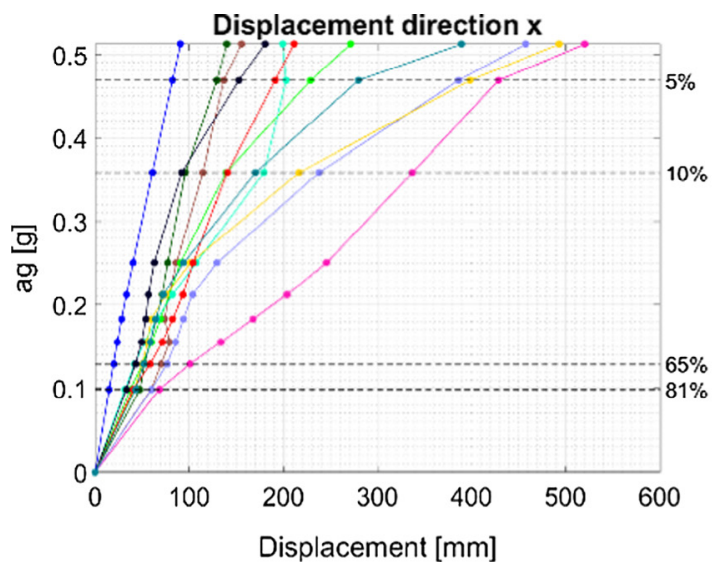

a. X-direction

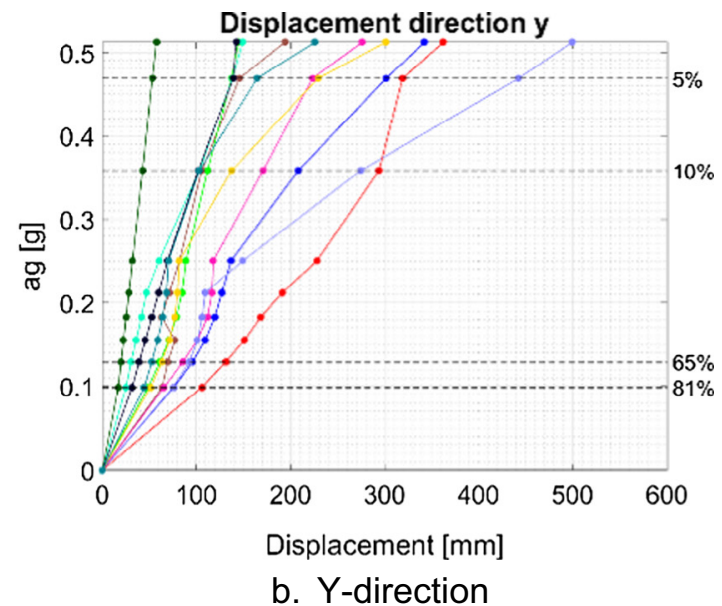

b. Y-direction

Fig. 23. Displacement $-a_{g}(g)-$ high seismicity (original structure). 


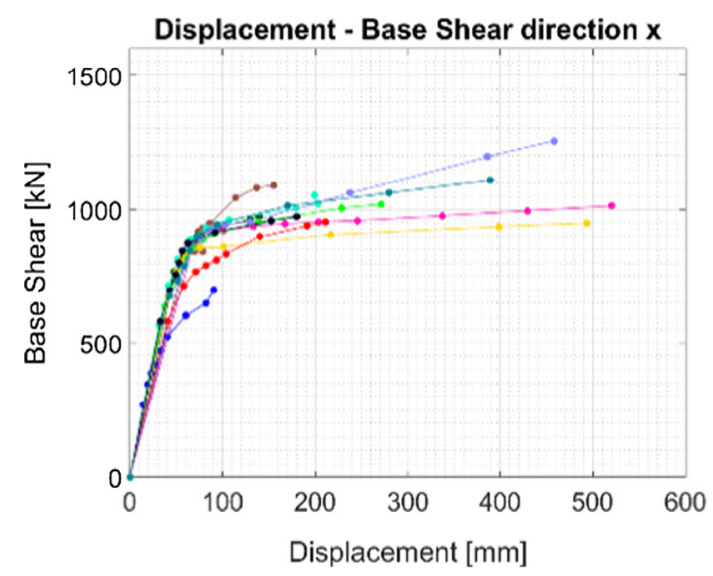

a. X-direction

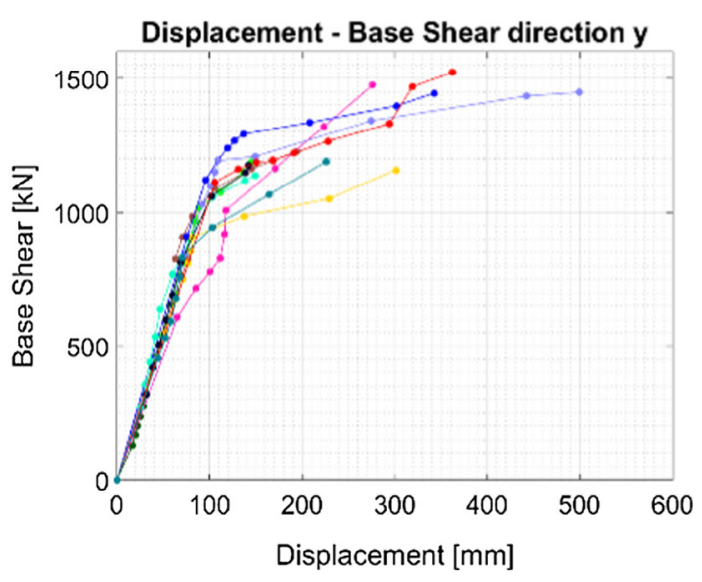

b. Y-direction

Fig. 24. Base shear vs Displacement - high seismicity (original structure).

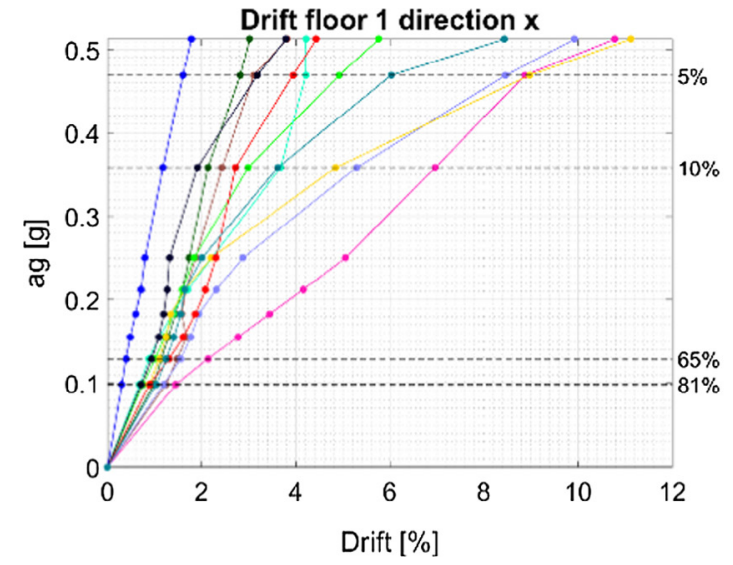

a. X-direction

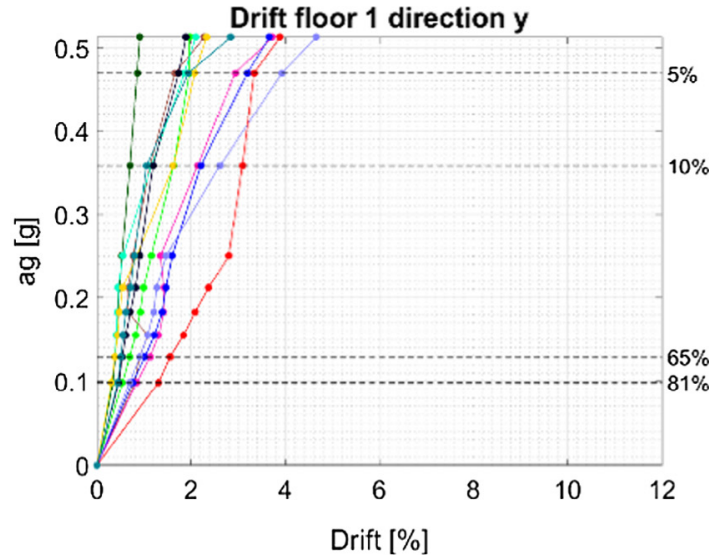

b. Y-direction

Fig. 25. $1^{\text {st }}$ level Inter-story drift vs $\mathrm{a}_{\mathrm{g}}(\mathrm{g})$ - high seismicity (original structure).

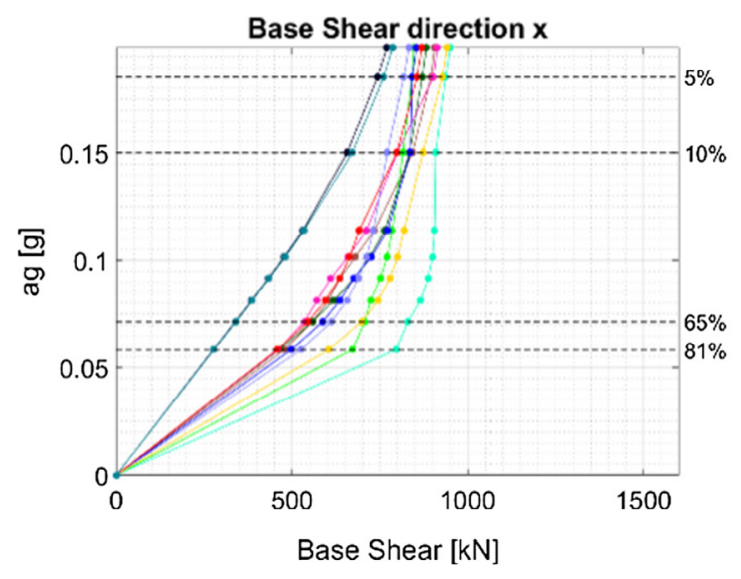

a. X-direction

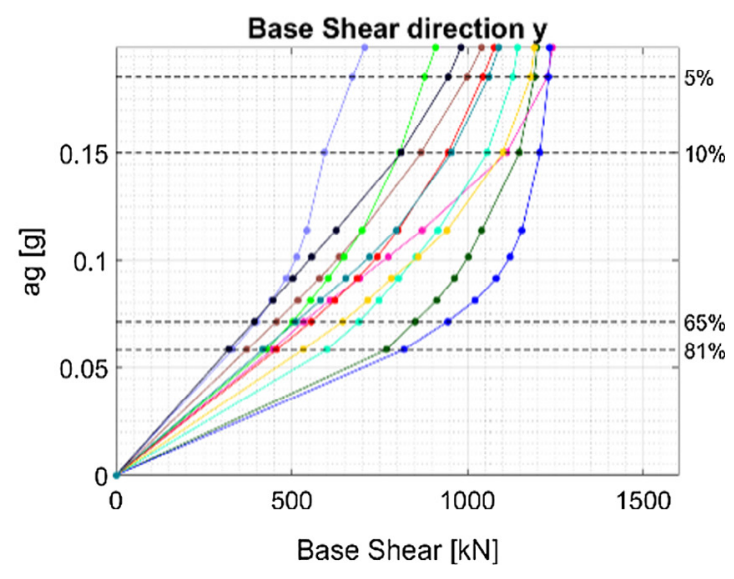

b. Y-direction

Fig. 26. Base shear vs $a_{g}(g)$ - low-to-moderate seismicity (original structure).

sequences of the potential local uplift of the individual forces on the structural behaviour is explicit.

To verify the isolation device model, a non-linear static analysis has been carried out, gradually applying a displacement up to $\pm 300 \mathrm{~mm}$ to the isolators as shown in Fig. 32.a. A period of $4 \mathrm{~s}$ hence a sliding stiffness $\mathrm{k}_{\mathrm{s}}$ equal to $0.187 \mathrm{kN} / \mathrm{mm}$ and $4 \%$ friction factor were assumed for all the isolators. Dependence of the friction coefficient on the static pressure has not been considered in 


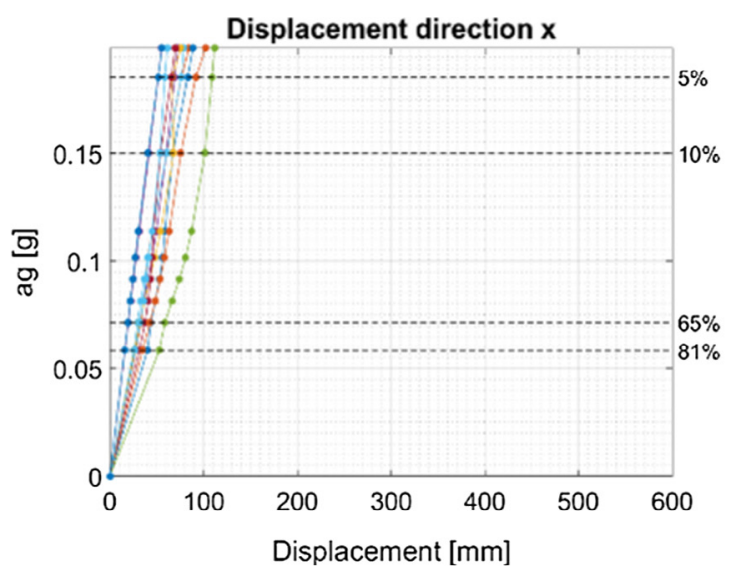

a. X-direction

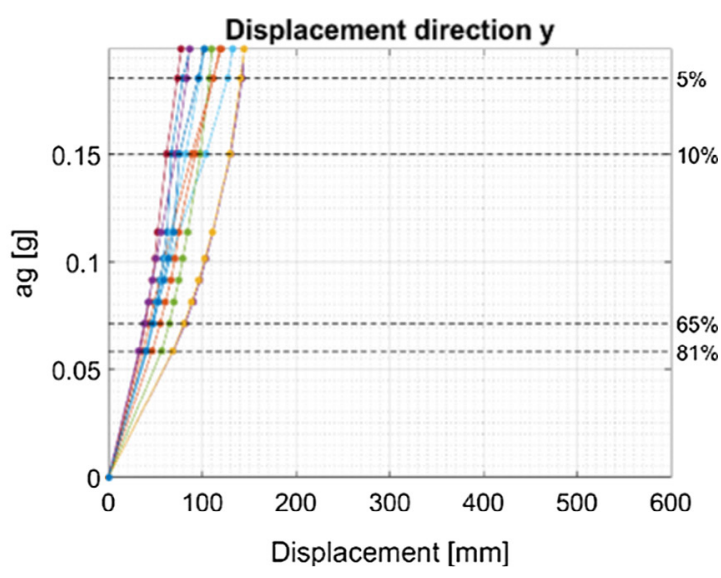

b. Y-direction

Fig. 27. Displacement vs $a_{g}(g)$ - low-to-moderate seismicity (original structure).

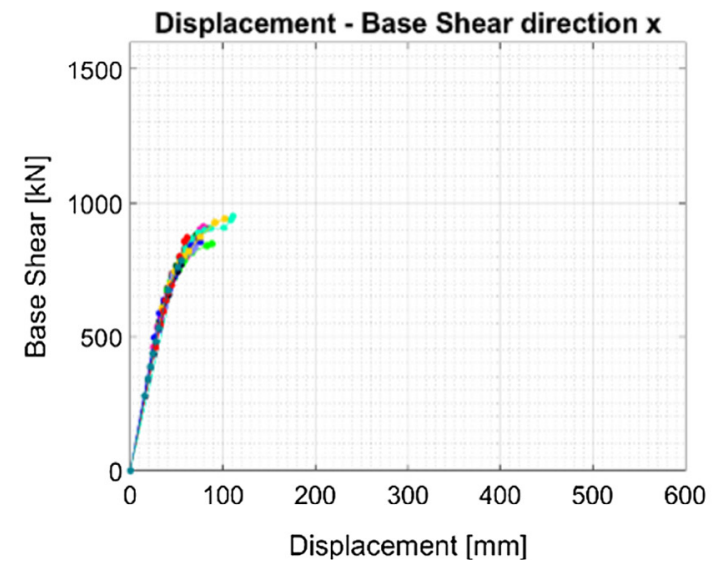

a. X-direction

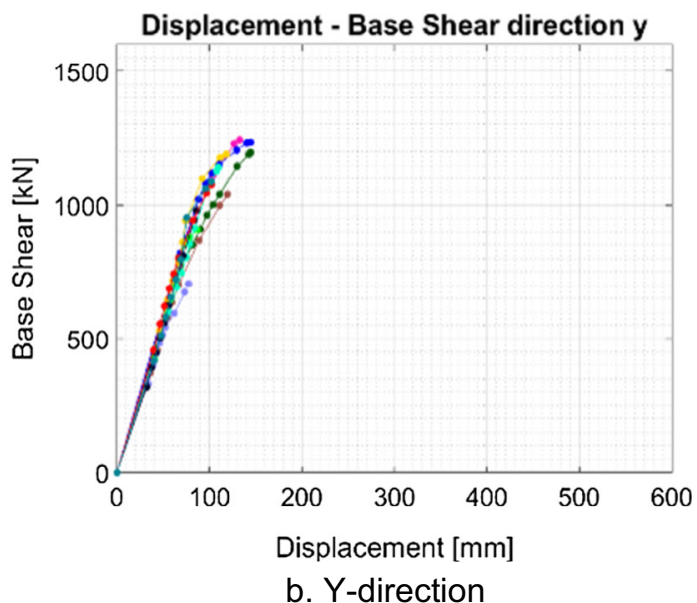

b. Y-direction

Fig. 28. Base shear vs Displacement - low-to-moderate seismicity (original structure).

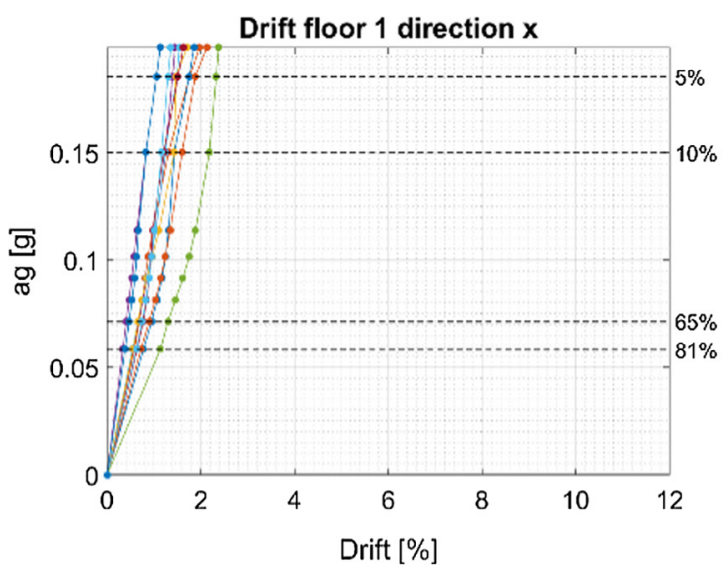

a. X-direction

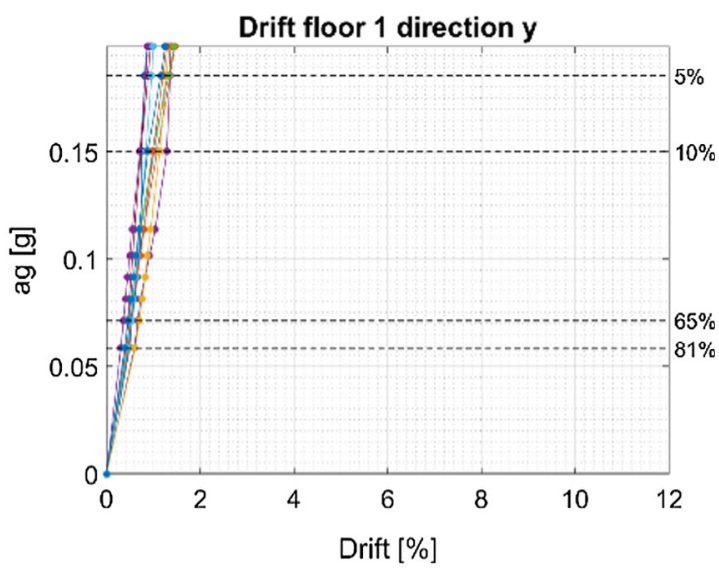

b. Y-direction

Fig. 29. $1^{\text {st }}$ level Inter-story drift vs $\mathrm{a}_{\mathrm{g}}(\mathrm{g})$ - low-to-moderate seismicity (original structure).

this case, since the advice of the producer of the isolation devices was to tune the friction material of each device to get a similar coefficient $(\sim 4 \%)$ compatible with the static pressure caused by the vertical loading on each isolator (the authors are aware that this coefficient may even change during the time-history due to the changing column axial load, however it has been assumed that such a change would not have a significant impact on the outcomes, since the results focus on comparing the isolated and non-isolated cases). The activation displacement of the isolation device has been estimated as $1 \%\left(D_{y}\right)$ of the total expected dis- 


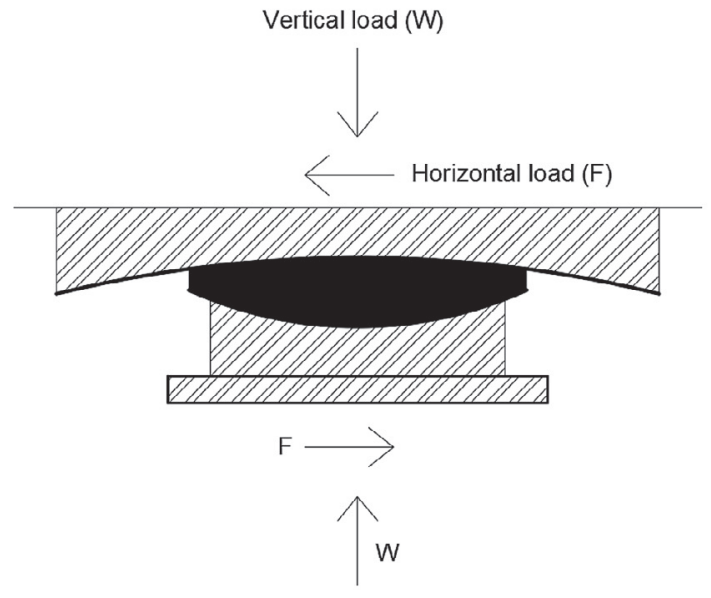

a. Forces acting on the device

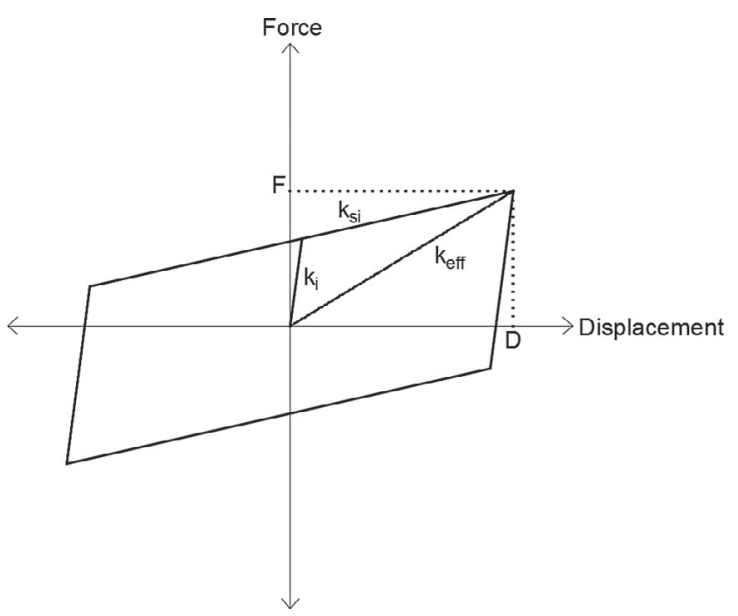

b. Force - displacement relationship

Fig. 30. Curved surface slider and its parameters.

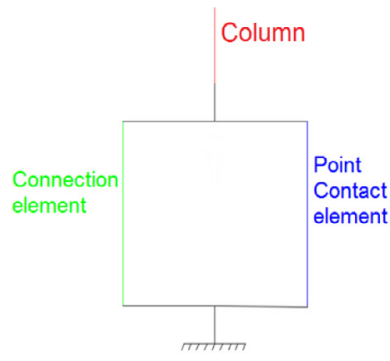

a. Isolation device model

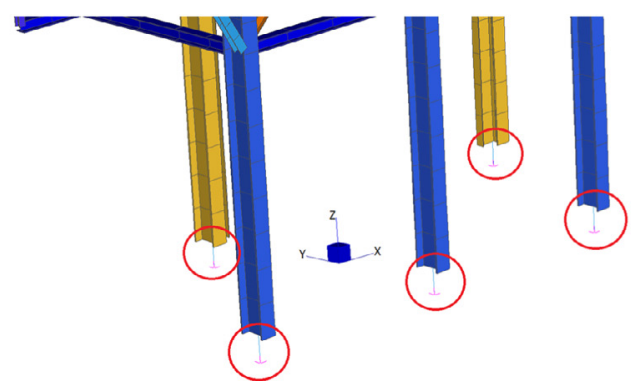

b. Global model

Fig. 31. Modelling of the isolator in Straus7.

placement (D), which results an initial stiffness $\left(k_{i}\right)$ in the order between $50-100$ times the secant stiffness $\left(k_{s}\right)$ as suggested by Naeim and Kelly [17]. Analytical calculation of the initial and effective stiffness result in $\mathrm{k}_{\mathrm{i} \text {,def }}$ and $\mathrm{k}_{\text {eff,def }}$ can be summarized with the following equations:

$k_{i, \text { def }}=\frac{\mu W}{D_{y} \cdot D}=\frac{0,04 \cdot 777,8 \mathrm{kN}}{0,01 \cdot 300 \mathrm{~mm}}=10,3 \frac{\mathrm{kN}}{\mathrm{mm}}$

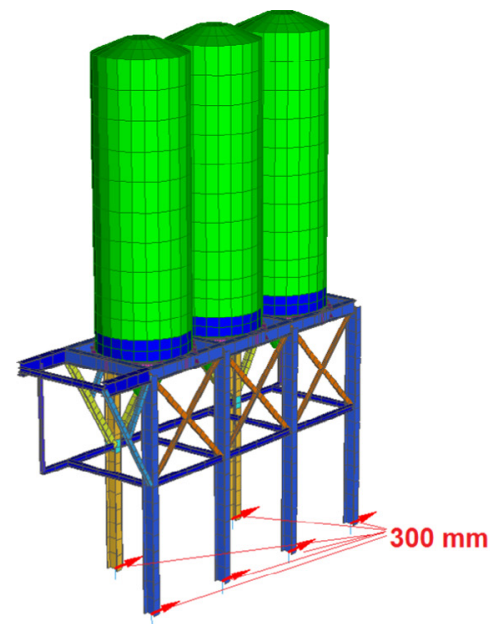

a. Displacements imposed to the isolators

$$
\begin{aligned}
k_{\text {eff }, \text { def }} & =\frac{\mu W}{300 \mathrm{~mm}}+W \cdot \frac{4 \cdot \pi^{2}}{\mathrm{~g} \cdot \mathrm{T}^{2}} \\
& \left.=\frac{777,8 \mathrm{kN}}{300 \mathrm{~mm}} \cdot 0,04+\frac{4 \cdot 3,14^{2}}{9810 \frac{\mathrm{mm}}{\mathrm{s}^{2}} \cdot(4 \mathrm{~s})^{2}} \cdot 300 \mathrm{~mm}\right) \\
& =0,29 \frac{\mathrm{kN}}{\mathrm{mm}}
\end{aligned}
$$

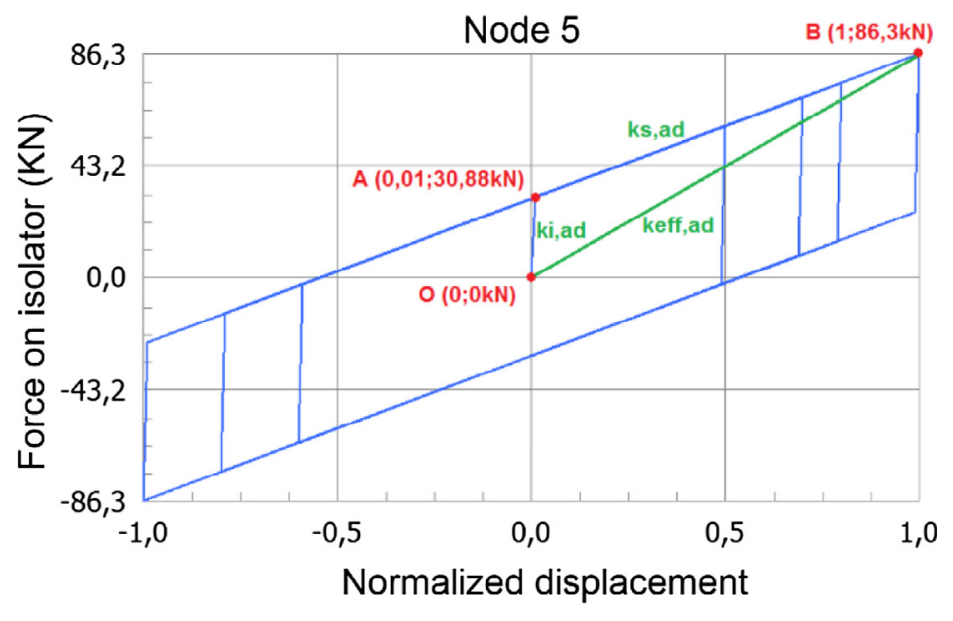

b. Constitutive law of the isolator in node 5 in terms forcedisplacement (period 4 seconds and friction factor $4 \%$ )

Fig. 32. Displacements imposed to the isolators. 
where,

$\mu$ : friction coefficient

W: Vertical load on the isolation device.

$\mathrm{T}$ : Response period of the isolator

g: Gravity acceleration

The force-displacement response of the isolator in the node 5 , obtained by the nonlinear static analysis is shown in Fig. 32.b, where the displacements are dimensionless.

From the non-linear static model, the initial and post-elastic isolator stiffness has been obtained normalized by the maximum displacement as respectively $\mathrm{k}_{\mathrm{i}}, \mathrm{k}_{\mathrm{s}}$ and $\mathrm{k}_{\mathrm{eff}}$ :

$k_{i}=\frac{y_{A}-y_{O}}{D \cdot\left(x_{A}-y_{O}\right)}=\frac{30,88 \mathrm{kN}}{300 \cdot(0,01)}=10,3 \frac{\mathrm{kN}}{\mathrm{mm}}$

$k_{s}=\frac{y_{B}-y_{A}}{D \cdot\left(x_{B}-y_{A}\right)}=\frac{86,3 \mathrm{kN}-30,88 \mathrm{kN}}{300 \cdot(1-0,01)}=0,187 \frac{\mathrm{kN}}{\mathrm{mm}}$

$k_{\text {eff }}=\frac{y_{B}-y_{O}}{D \cdot\left(x_{B}-y_{O}\right)}=0,29 \frac{\mathrm{kN}}{\mathrm{mm}}$

It can be noted that the initial, post-elastic and effective stiffness values obtained from the nonlinear static analysis (Eqs. (7) and (9)) coincide with those assumed and analytically calculated (Eqs. (5) and (6)). Therefore, it can be stated that the numerical modelling of the isolation device represents correctly the analytical device behaviour.

As a second step, horizontal stiffness and friction parameters have been iterated to find an optimal balance between best structural performance and acceptable maximum displacements. After several iterations, the best solution has been obtained by using 6 seismic isolators connected by a rigid diaphragm made of as a horizontal steel frame with beams and horizontal bracing elements at ground level as shown in Fig. 33. Solutions without a rigid diaphragm did not provide feasible results because of excessive global torsional behaviour.

Table 7 shows the most suitable isolator properties obtained after several iterations. Different horizontal stiffness values have been used for different supports, which are calibrated according to the vertical reaction force under full-silo gravity loading condition. The positions of the nodes $1,7,5,6,20$ and 21 were shown in Fig. 17.

\subsection{Nonlinear analysis results - retrofitted structure}

The results of the modal analysis are reported in Table 8. From Fig. 34 it can be observed that in the second fundamental mode, there is no more a global torsional component, which means that with the designed base isolation system, the asymmetry problem of the original structure has been solved.

To quantify the performance of the selected isolators, seven nonlinear time history analysis have been performed. Max/min and average values of isolator displacements and residual displacements obtained from each accelerogram are shown in Table 9. The dispersion of the results can be noted from the comparison of the individual and the average values. Although the European seismic codes permit considering the average value of seven earthquake time history analyses, from the practical point of view, such a large dispersion between the isolator displacements should be paid attention while choosing the final dimensions of the isolation device to accommodate larger than average displacements.

$\mathrm{Max} / \mathrm{min}$ and average values of base shear and relative displacements of the structure's mass center obtained from each accelerogram are shown in Table 10. Significant reduction in the

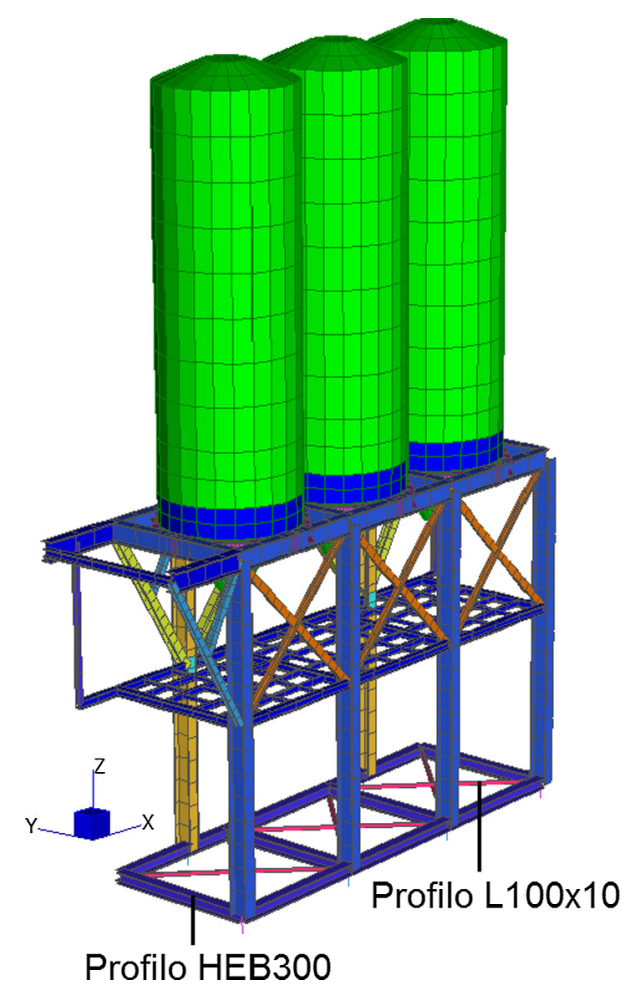

Fig. 33. Retrofitted silo system.

Table 7

Isolator properties and nodal reactions.

\begin{tabular}{ll}
\hline Friction & $4 \%$ \\
\hline $\mathrm{T}_{\mathrm{is}}$ & $4 \mathrm{~s}$ \\
$\mathrm{k}_{1,7}$ & $0,09 \mathrm{kN} / \mathrm{mm}$ \\
$\mathrm{k}_{5,6}$ & $0,2 \mathrm{kN} / \mathrm{mm}$ \\
$\mathrm{k}_{20,21}$ & $0,274 \mathrm{kN} / \mathrm{mm}$ \\
$\mathrm{k}_{\mathrm{v}}$ & $3000 \mathrm{kN} / \mathrm{mm}$ \\
\hline
\end{tabular}

average base shear thanks to the seismic isolation system can be observed from Fig. 35.

To make a comparison in terms of displacements between the original and the retrofitted structures, the average displacements of the retrofitted structure obtained from the nonlinear dynamic analysis have been multiplied by a reliability factor of 1.2 as recommend in EN1998-1-1 section 10.3.(2)P [47]. Table 11 compares the maximum displacements obtained at the gravity center of the structure, which are reduced by $53 \%$ and $27 \%$ respectively in $\mathrm{x}$ and $\mathrm{y}$ directions, thanks to the seismic isolation system. Reducing the displacements of the silos therefore reduces the possibility of rocking effect and local instabilities between the supporting structure and the silos.

Comparisons in terms of inter-story drifts are shown in Fig. 36 and Table 12. The weaker floor in the longitudinal direction of the structure is the first one, as the second floor is braced. The vulnerability of the $1^{\text {st }}$ floor to the soft-story mechanism is significantly reduced. In the x-direction (braced), the inter-story drift is reduced to $1.24 \%$ from $3.49 \%$ (approximately $64 \%$ reduction thanks to the isolation system). In y-direction (non-braced), a reduction of 35\%for the first floor and 53\% for the second floor have been observed.

The inelastic deformations observed in the structural elements have been represented by means of a yield index (changes between 0 and 1.00 , being 1.00 fully plastic cross section). The comparison between the original and retrofitted structure is shown in Fig. 37, 
Table 8

Modal analysis results (PF-X, PF-y, PF-RZ respectively represents translational X and Y and rotational Z mass participation) (retrofitted structure).

\begin{tabular}{|c|c|c|c|c|}
\hline Mode & $\mathrm{T}[\mathrm{s}]$ & PF-X (\%) & PF-y (\%) & PF-Rz (\%) \\
\hline 1 & 4.5 & 0 & 99.9 & 18.9 \\
\hline 2 & 4.17 & 99.9 & 0 & 2.3 \\
\hline 3 & 3.45 & 0 & 0 & 8.6 \\
\hline
\end{tabular}

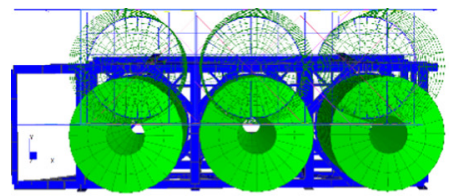

1st mode

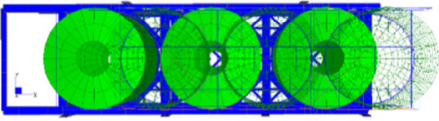

2nd mode

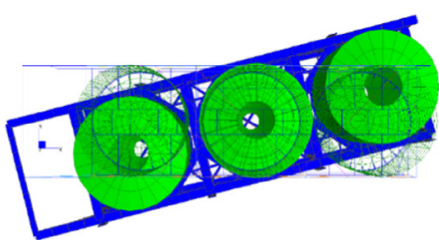

3rd mode

Fig. 34. First three fundamental modal shapes (retrofitted structure).

Table 9

Max/Min and average displacements (retrofitted structure).

\begin{tabular}{|c|c|c|c|c|}
\hline \multirow[t]{2}{*}{ Seismic Input } & \multicolumn{2}{|c|}{ Max displacement of isolators $[\mathrm{cm}]$} & \multicolumn{2}{|c|}{$\begin{array}{l}\text { Max residual displacement of isolators } \\
{[\mathrm{cm}]}\end{array}$} \\
\hline & $\mathrm{x}$ & $\mathrm{y}$ & $\mathrm{x}$ & $\mathrm{y}$ \\
\hline ED74 & 14,0 & 24,5 & 3,72 & 4,21 \\
\hline ED196 & 3,8 & 2,6 & 1,14 & 1,64 \\
\hline ED535 & 34,5 & 29,0 & 0,84 & 1,13 \\
\hline ED6349 & 5,6 & 29,0 & 1,43 & 1,45 \\
\hline IN113 & 21,2 & 11,9 & 3,23 & 2,21 \\
\hline IN331 & 29,3 & 41,2 & 1,58 & 2,31 \\
\hline IN461 & 21,3 & 33,9 & 0,79 & 2,06 \\
\hline Avg & 18,5 & 24,2 & 1,86 & 2,12 \\
\hline
\end{tabular}

Table 10

Max/Min displacements and base shear (retrofitted structure).

\begin{tabular}{|c|c|c|c|c|}
\hline \multirow[t]{2}{*}{ Seismic Input } & \multicolumn{2}{|c|}{ Base shear [kN] } & \multicolumn{2}{|c|}{$\begin{array}{l}\text { Relative displacements of structure mass } \\
\text { center }[\mathrm{cm}]\end{array}$} \\
\hline & $\mathrm{x}$ & $\mathrm{y}$ & $\mathrm{x}$ & $\mathrm{y}$ \\
\hline ED74 & 374,5 & 287,3 & 5,1 & 9,4 \\
\hline ED196 & 272,0 & 138,4 & 3,8 & 5,2 \\
\hline ED535 & 538,7 & 303,3 & 8,8 & 9,3 \\
\hline ED6349 & 165,1 & 419,0 & 2,2 & 11,1 \\
\hline IN113 & 487,1 & 167,4 & 7,1 & 5,8 \\
\hline IN331 & 607,8 & 513,3 & 11,6 & 17,4 \\
\hline IN461 & 480,1 & 448,2 & 7,4 & 14,4 \\
\hline Average & 417,9 & 325,3 & 6,6 & 10,4 \\
\hline
\end{tabular}

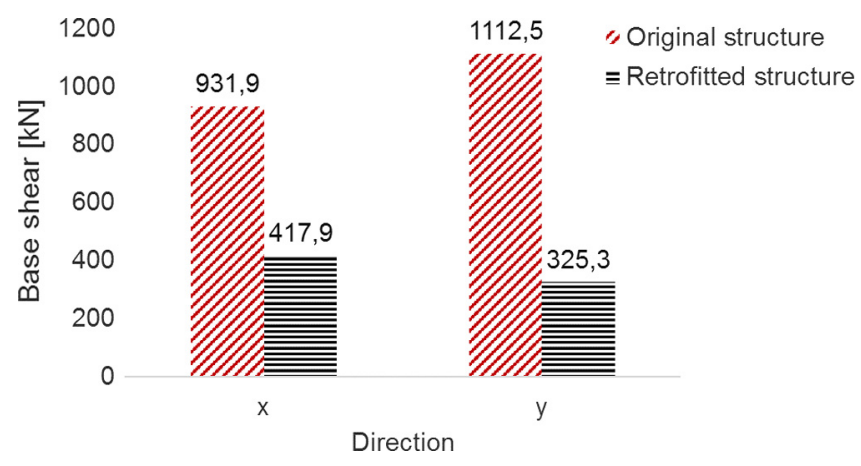

Fig. 35. Average base shear comparison between original and retrofitted structure
Table 11

Comparison of maximum displacement of the mass center.

\begin{tabular}{clll}
\hline Direction & $\begin{array}{l}\text { Original } \\
\text { structure } \\
\text { (absolute } \\
\text { displacement) }\end{array}$ & $\begin{array}{l}\text { Retrofitted structure (average } \\
\text { relative displacement } \\
\text { multiplied with reliability } \\
\text { magnification factor [47]) }\end{array}$ & Reduction \\
\hline $\mathrm{x}$ & $16,7 \mathrm{~cm}$ & $7,9 \mathrm{~cm}$ & $53 \%$ \\
$\mathrm{y}$ & $17,1 \mathrm{~cm}$ & $12,5 \mathrm{~cm}$ & $27 \%$ \\
\hline
\end{tabular}

with reference to the ED74 accelerogram. In this case, the retrofitted structure did not have any inelastic deformation.

In the analyses, under some of the accelerograms that are creating particularly high seismic demands, uplift has been observed. From the inelastic deformation index of the isolated structures, it seems that the local uplift observed in some of the isolators did not overstress the structural elements. Although with traditional 


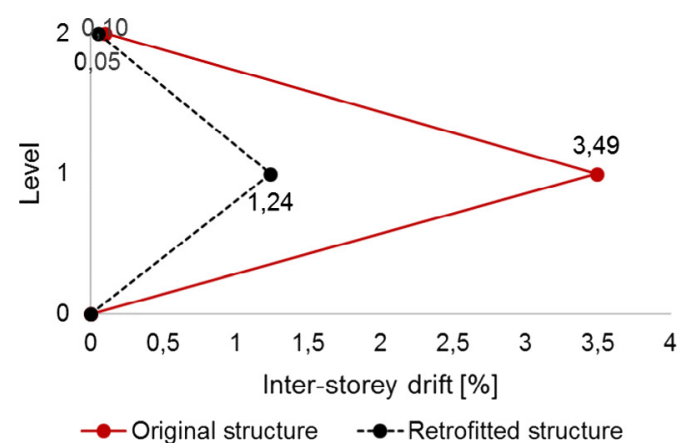

a. X-direction

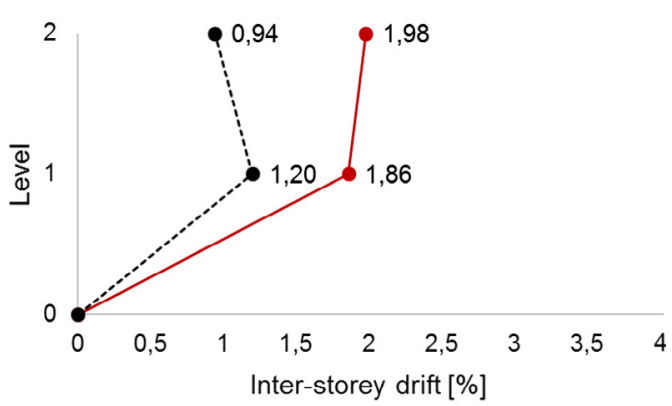

$\rightarrow$ Original structure $\quad-\bullet-$ Retrofitted structure

b. Y-direction

Fig. 36. Inter-story drift comparisons between the original and the retrofitted structures.

Table 12

Comparisons in terms of inter-story drifts.

\begin{tabular}{|c|c|c|c|c|}
\hline Level & Direction & Fixed-base structure & Retrofitted structure & Reduction \\
\hline \multirow[t]{2}{*}{1} & $\mathrm{x}$ & $3,49 \%$ & $1,24 \%$ & $64 \%$ \\
\hline & $\mathrm{y}$ & $1,86 \%$ & $1,20 \%$ & $35 \%$ \\
\hline \multirow[t]{2}{*}{2} & $\mathrm{x}$ & $0,10 \%$ & $0,05 \%$ & $50 \%$ \\
\hline & $\mathrm{y}$ & $1,98 \%$ & $0,94 \%$ & $53 \%$ \\
\hline
\end{tabular}

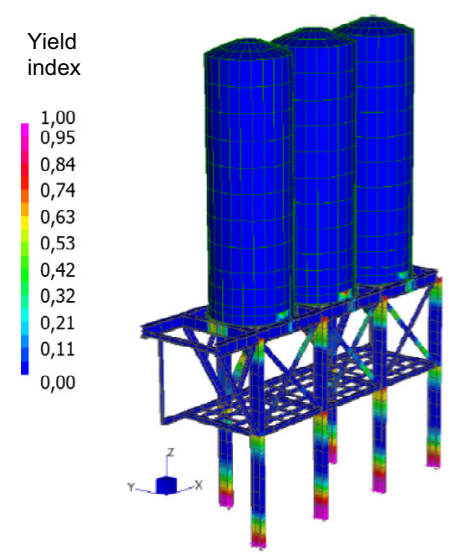

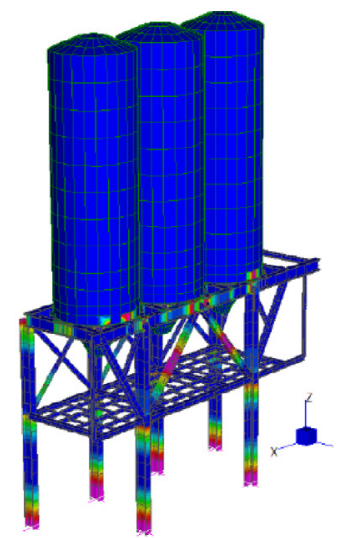

a. Original structure

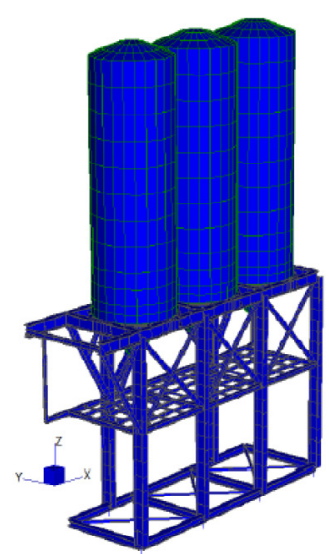

b. Retrofitted structure

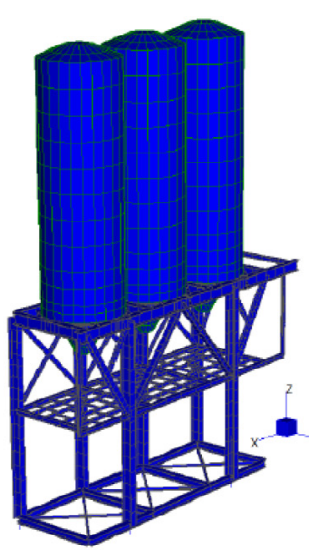

Fig. 37. Yield index of the original and the retrofitted structures.
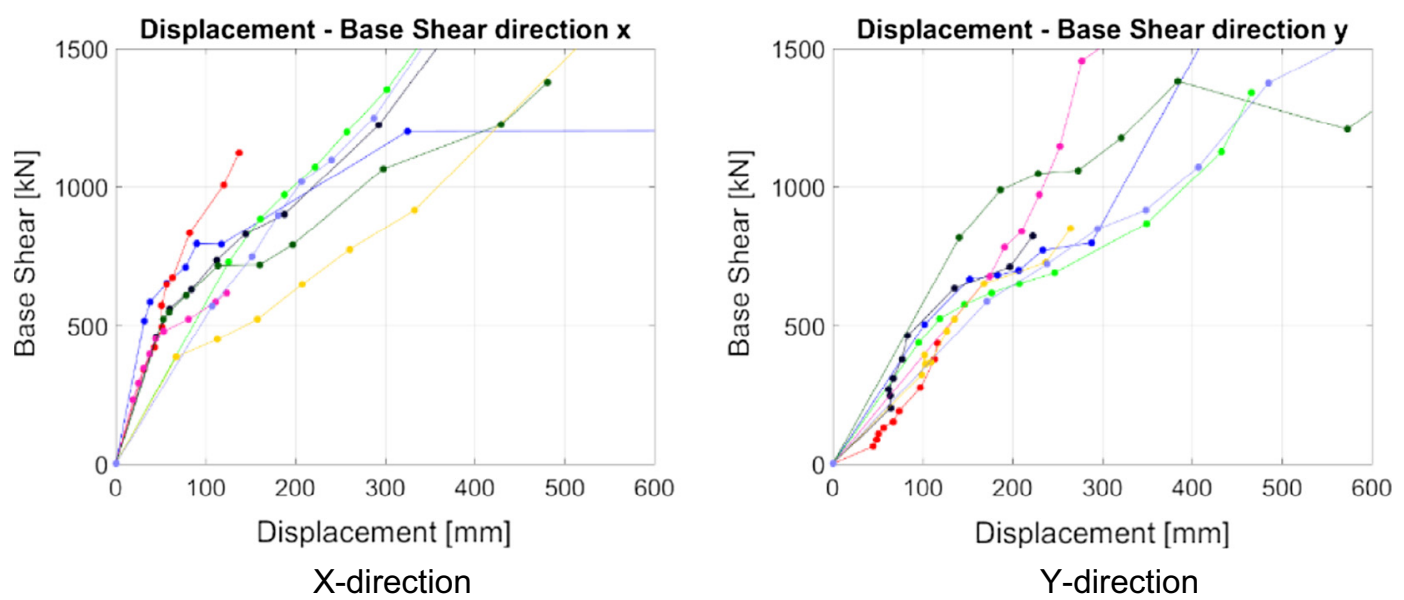

Fig. 38. Base shear vs $a_{g}(g)$ - high seismicity (retrofitted structure). 


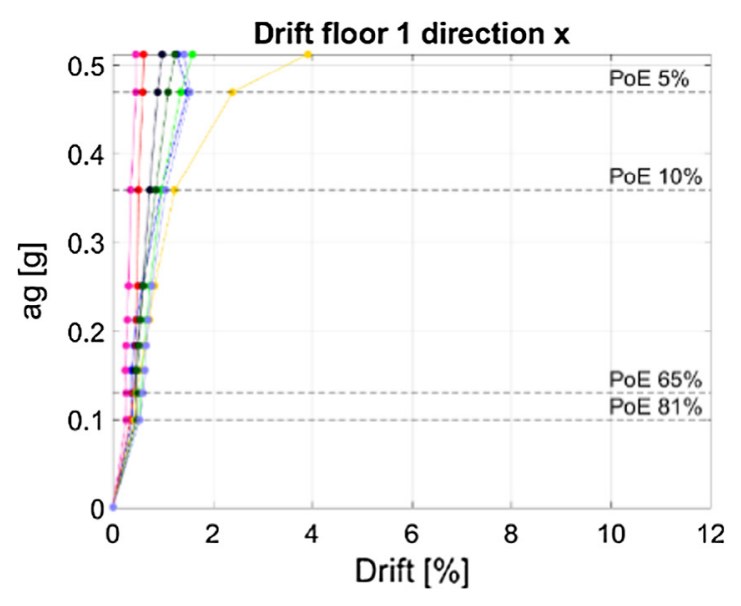

c. X-direction

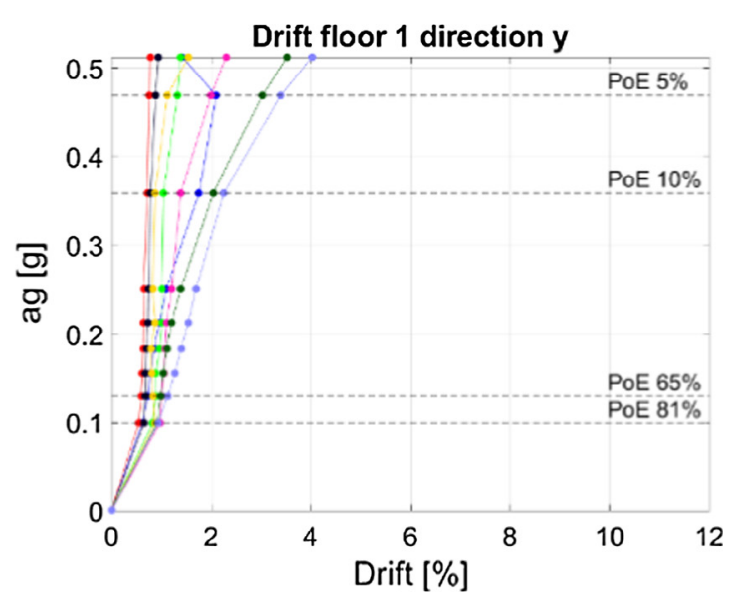

d. Y-direction

Fig. 39. $1^{\text {st }}$ level Inter-story drift vs $a_{g}(g)$ - high seismicity. (retrofitted structure)

Table 13

Damage states corresponding to the inter-story drift.

\begin{tabular}{llll}
\hline $\mathrm{L}_{\mathrm{d}}$ & Damage state & Inter-story drift [\%] & Color/line \\
\hline 0 & No structural damage & $<0,1$ & \\
1 & Slight structural damage & $0,1-0,25$ & $\ldots \ldots \ldots$ \\
2 & Low-moderate structural damage & $0,25-0,5$ & - \\
3 & Moderate structural damage & $0,5-1$ & - \\
4 & Heavy structural damage & $1-1,5$ & - \\
5 & Collapse & $>1,5$ & - \\
\hline
\end{tabular}

curved surface sliders, uplift physically cannot be avoided, the problem may be solved with a modification of the isolation device to restrain it against uplift, since adding extra weight on the structure in this case would not be feasible (unlike commonly applied in the case of bridges). There are some studies in the literature studying this aspect $[52,53]$.

IDA analyses have been performed in the high-seismicity context. Base shear, displacement and inter-story drift response parameters have been obtained, and global capacity curves have been plotted (Fig. 38, Fig. 39). While the global elasto-plastic behaviour was evident in case of the original structure, retrofitted structure responds in an almost linear manner to the increase in global base shear forces with increasing scale factors.

Fig. 39 shows the reduced inter-story drifts of the first floor in case of retrofitted structure. Most importantly, the soft-story behaviour observed in the original structure has been eliminated thanks to the seismic retrofitting, as can be observed from the very low inter-story drift ratios of the first floor.

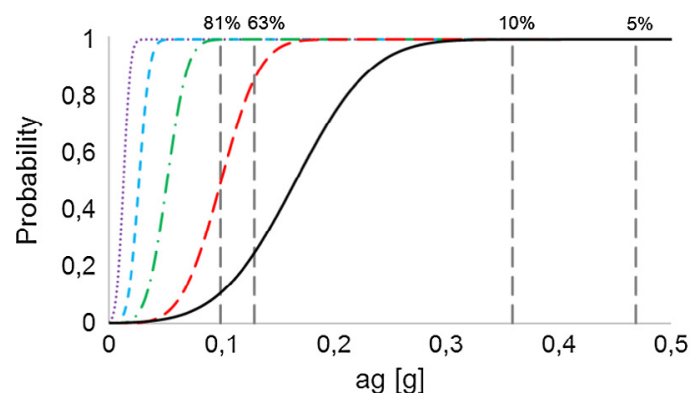

a. Original structure
Finally, fragility curves have been plotted according to the damage states defined for different inter-story drift levels, for the original and retrofitted structure. In these curves, peak accelerations corresponding to the $5 \%, 10 \%, 63 \%$ e $81 \%$ probability of occurrences have been defined. These curves express the probability of reaching a certain damage state corresponding to the peak acceleration ag. The probability of reaching a certain level of damage $d_{s}$ corresponding to the peak acceleration ag is estimated by the following formula:

$P\left[d s \mid a_{g}\right]=\Phi\left[\frac{1}{\beta_{d s}} \ln \left(\frac{a_{g}}{\bar{a}_{g, d s}}\right)\right]$

where $\bar{a}_{g, d s}$ is the average value of peak accelerations for which the structure reaches the threshold damage $d_{s}, \beta_{d s}$ is the standard deviation of natural logarithm of the spectral displacement for the damage level $d_{s}$, and $\Phi$ is the cumulative normal standard function $[16,54]$.

The damage threshold can be defined in several ways. For building structures, its definition in terms of inter-story drift ratio usually provides reliable results as shown by several researchers $[16,55,56]$. In this paper, based on the inter-story drift ratios, five damage states have been defined according to the "Scala Macrosismica Europea del 1998 (EMS, 1998)" [57], with 5 levels of $\mathrm{L}_{\mathrm{d}}$, from "slight structural damage" to the "collapse". This is shown in Table 13, with the same line legends that are used in Fig. 40. Increasing inter-story drift ratios imply higher risk for a global collapse caused by a soft-story behaviour, which is considered as the most critical situation in the case study under investigation of this article.

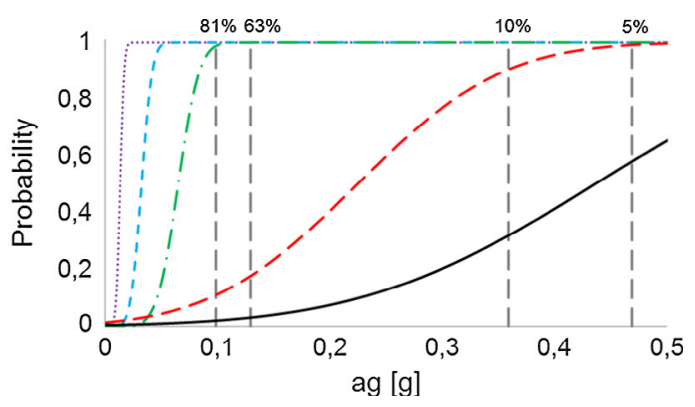

b. Retrofitted structure

Fig. 40. Fragility curves for high seismicity. 
Comparison of the fragility curves shows how the retrofitting solution reduced the seismic vulnerability of the original structure. The probability of the heavy structural damage is $\% 85$ for the original structure, $18 \%$ for the retrofitted one for an earthquake with a PoE of $63 \%$ in 50 years. The probability of having a structural collapse for an earthquake with a PoE of $5 \%$ in 50 years is almost certain (99\%) for the original structure, while this probability is $55 \%$ for the retrofitted structure.

\section{Conclusions}

In this paper, seismic vulnerability of an existing industrial steel silo group has been presented, and a specific retrofitting solution has been proposed by means of base isolation devices. A threedimensional model of the original and retrofitted structure has been developed using nonlinear plate elements and distributed plasticity approach, and analyzed by means of incremental dynamic analysis method. Nonlinear time-history analyses have highlighted the failure zones in the supporting steel structure. Numerically obtained failure mechanisms represented the typical damages suffered by elevated silos after the recent devastating earthquakes, such as high stress concentrations in the connections, inelastic deformations at the column bases and at the first level column ends which induces soft story collapse mechanism, and yielding of the bracings. In order to avoid these criticalities, a single curved surface slider has been designed and incremental dynamic analyses have been performed to compare the seismic performance before and after retrofitting. Benefits of the base isolation solution has been quantified in terms of inelastic deformations, global horizontal shear, inter-story drifts, isolator displacements, and residual displacements.

All response parameters have been largely reduced after the silo-group was retrofitted by curved surface sliders. The softstory vulnerability of the original structure has been also eliminated, which decreased significantly the collapse risk of under strong earthquakes, which was observed from the fragility curves plotted corresponding to the damage states defined for different inter-story drift levels. In conclusion, base isolation devices represented an efficient retrofitting solution for the existing elevated silos, decoupling the superstructure from the strong ground shaking. This study showed the feasibility of this method on an existing elevated silo group. With an appropriate design compatible with the geometry of the structure and the content of the silos, the results can be extended also to other examples.

\section{Acknowledgements}

This article presents the results of numerical analyses performed within PROINDUSTRY project (Seismic protection of industrialplants by enhanced steel based systems), which is carried out with the financial grant of the Research Program of the Research Fund for Coal and Steel of the European Commission (RFSR-CT2013-00019). The project consortium was coordinated by the University of Pisa. The authors of this article Alper Kanyilmaz and Carlo Andrea Castiglioni were the scientific consultants of the Neapolis University Pafos, which was one of the beneficiaries of the PROINDUSTRY Project.

\section{References}

[1] Rotter JM. Silo and hopper design for strength. In: McGlinchey Don, editor. Bulk solids handling: equipment selection and operation. Blackwell Publishing Ltd; 2008. ISBN: 978-1-405-15825-1.

[2] Rotter JM. Silos and tanks in research and practice: state of the art and current challenges. Symp Int Assoc Shell Spat Struct 2009:65-76.
[3] Salvatore W, Morelli F, De Pasquale E, Tesi M, Degee H, Hofffmeister B, et al. EU-RFCS Project PROINDUSTRY (Seismic Protection of Industrial Plants by Enhanced Steel Based Systems; 2013). Final Report 2017.

[4] ASCE/SEI. ASCE/SEI 7-10 Minimum Design Loads for Buildings and Other Structures. 2010. DOI: 10.1061/9780784412916.

[5] Dogangun A, Karaca Z, Durmus A, Sezen H. Cause of damage and failures in silo structures. J Perform Constr Fac 2009;23(2). http://dx.doi.org/10.1061/(ASCE) 0887-3828(2009)23:2(65). ASCE ISSN 0887-3828/2009/2-65-71.

[6] Braga F, Morelli F, Salvatore W. A macroseismic approach for the evaluation of seismic risk. In: Kruis J, Tsompanakis Y, Topping BHV, editors. Proc. Fifteenth Int. Conf. Civil, Struct. Environ. Eng. Comput.. Stirlingshire, Scotl.: Civil-Comp Press; 2015. p. 1-12.

[7] Housner GW. The dynamic behaviour of water tanks. Bull Seismol Soc Am 1963;53:381-7.

[8] Haroun MA. Vibration studies and tests of liquid storage tanks. Earthq Eng Struct Dyn 1983;11:179-206. http://dx.doi.org/10.1002/eqe.4290110204.

[9] Somerville P, Graves R. Conditions that give rise to unusually large long period ground motions. Struct Des Tall Build 1993;2:211-32. http://dx.doi.org/ $10.1002 /$ tal.4320020304

[10] Jaiswal OR, Rai DC, Jain SK. Review of seismic codes on liquid-containing tanks. Earthq Spectra 2007;23:239-60. http://dx.doi.org/10.1193/1.2428341.

[11] Castiglioni CA, Kanyilmaz A. Simplified numerical modeling of elevated silos for nonlinear dynamic analysis. Ing Sismica 2015;33(1-2):5-14.

[12] Pinkawa M, Hoffmeister B, Feldmann M. Performance assessment of seismic retrofitting measures on silo structures using innovative seismic protection systems. ECCOMAS Congr. 2016 VII Eur. Congr. Comput. Methods Appl. Sci. Eng. M. Papadrakakis, V. Papadopoulos, G. Stefanou, V. Plevris, 2016, p. 5851-67.

[13] Morelli F, Piscini A, Salvatore W. Seismic retrofit of an industrial structure through an innovative self-centering hysteretic damper: Modelling, analysis and optimization. Proc. VII Eur. Congr. Comput. Methods Appl. Sci. Eng. M. Papadrakakis, V. Papadopoulos, G. Stefanou, V. Plevris (Editors), Crete Island, Greece, 2016, p. 5-10.

[14] Uckan E, Akbas B, Shen J, Wen R, Turandar K, Erdik M. Seismic performance of elevated steel silos during Van earthquake, October 23, 2011. Nat Hazards 2015;75:265-87. http://dx.doi.org/10.1007/s11069-014-1319-9.

[15] Aydan O, Ulusay R, Kumsar H, Konagai K. Site investigation and engineering evaluation of the van earthquakes. Japan Soc Civ Eng 2012.

[16] Güneyisi EM, Altay G. Seismic fragility assessment of effectiveness of viscous dampers in $\mathrm{R} / \mathrm{C}$ buildings under scenario earthquakes. Struct Saf 2008;30:461-80. http://dx.doi.org/10.1016/i.strusafe.2007.06.001.

[17] Naeim F, Kelly JM. Design of seismic isolated structures: from theory to practice. Earthq Spectra 2000;16:709-10. http://dx.doi.org/10.1193/ 1.1586135 .

[18] Castaldo P, Palazzo B, Della Vecchia P. Seismic reliability of base-isolated structures with friction pendulum bearings. Eng Struct 2015;95:80-93. http:// dx.doi.org/10.1016/j.engstruct.2015.03.053.

[19] Skinner R, Robinson WH, McVerry G. An introduction to seismic isolation. John Wiley Sons 1993;12:449. 10.1016/0267-7261(93)90010-O.

[20] Dall'Asta A, Leoni G, Morelli F, Salvatore W, Zona A. An innovative seismicresistant steel frame with reinforced concrete infill walls. Eng Struct 2017;141:144-58. http://dx.doi.org/10.1016/i.engstruct.2017.03.019.

[21] Quaglini V, Bocciarelli M, Gandelli E, Dubini P. Numerical assessment of frictional heating in sliding bearings for seismic isolation. J Earthquake Eng 2014;18(8):1198-216. http://dx.doi.org/10.1080/13632469.2014.924890.

[22] Valente M, Castiglioni CA, Kanyilmaz A. Welded fuses for dissipative beam-tocolumn connections of composite steel frames: numerical analyses. J Constr Steel Res 2017;128:498-511. http://dx.doi.org/10.1016/j.jcsr.2016.09.003.

[23] Valente M, Castiglioni CA, Kanyilmaz A. Dissipative devices for earthquake resistant composite steel structures: bolted versus welded solution. Bull Earthq Eng 2016;14:3613-39. http://dx.doi.org/10.1007/s10518-016-0002-9.

[24] Valente M, Castiglioni CA, Kanyilmaz A. Numerical investigations of repairable dissipative bolted fuses for earthquake resistant composite steel frames. Eng Struct 2017;131:275-92. http://dx.doi.org/10.1016/j.jcsr.2016.09.003.

[25] Castiglioni CA, Kanyilmaz A, Calado L. Experimental analysis of seismic resistant composite steel frames with dissipative devices. J Constr Steel Res 2012;76:1-12. http://dx.doi.org/10.1016/j.jcsr.2012.03.027.

[26] Braconi A, Morelli F, Salvatore W. Development, design and experimental validation of a steel self-centering device (SSCD) for seismic protection of buildings. Bull Earthq Eng 2012;10(6):1915-41. http://dx.doi.org/10.1007/ s10518-012-9380-9.

[27] Fagà E, Ceresa P, Nascimbene R, Moratti M, Pavese A. Modelling curved surface sliding bearings with bilinear constitutive law: effects on the response of seismically isolated buildings. Mater Struct 2012;49(6):2179-96. http://dx. doi.org/10.1617/s11527-015-0642-2.

[28] Martelli A, Forni M, Clemente P. Recent worldwide application of seismic isolation and energy dissipation and conditions for their correct use. $15 \mathrm{Th}$ WORLD Conf Earthq Eng LISBON, Port 2012, pp. 1-12, DOI: 10.1201/b11396-3.

[29] Phan HN, Paolacci F, Corritore D, Akbas B, Uckan E, Shen JJ. Seismic vulnerability mitigation of liquefied gas tanks using concave sliding bearings. Bull Earthq Eng 2016;14:3283-99. http://dx.doi.org/10.1007/ s10518-016-9939-y.

[30] Paolacci F. On the effectiveness of two isolation systems for the seismic protection of elevated tanks. J Press Vessel Technol 2015;137:31801. http://dx. doi.org/10.1115/1.4029590. 
[31] Giannini R, Paolacci F, Angelis M De, Ciucci M. Shaking Table Tests Upon a Base Isolated Steel Liquid storage tank. In: 14th world conference on earthquake engineering; 12-17 October; 2008.

[32] Paolacci F, Giannini R, De Angelis M. Seismic response mitigation of chemical plant components by passive control techniques. J Loss Prev Process Ind 2013;26:924-35. http://dx.doi.org/10.1016/i.jlp.2013.03.003.

[33] Italiano EN. Progettazione delle strutture per la resistenza sismica Parte 4: Silos, serbatoi e condotte. 2009.

[34] Information T. MAURER Seismic Isolation Systems 2003.

[35] Gigliotti R, Faggella M, Rossi E, Ventrella M, Braga F. Performance based earthquake assessment of an industrial silos structure. ECCOMAS Congr 2016 VII Eur Congr Comput Methods Appl Sci Eng 2016:5-10.

[36] Faggella M, Laguardia R, Gigliotti R, Morelli F, Braga F, Salvatore W. Performance-Based Nonlinear Response History Analysis Framework for the “Proindustry" Project. Proc. VII Eur. Congr. Comput. Methods Appl. Sci. Eng. M. Papadrakakis, V. Papadopoulos, G. Stefanou, V. Plevris (Editors), Crete Island, Greece, 2016, p. 5-10.

[37] Vamvatsikos D, Cornell CA. Incremental dynamic analysis. Earthq Eng Struct Dyn 2002;514:491-514. http://dx.doi.org/10.1002/ege.141.

[38] Sabelli R. Research on improving the design and analysis of earthquakeresistant steel-braced frames. NEHRP Prof Fellowsh Report EERI 2001:1-142.

[39] Avery P, Mahendran M. Distributed plasticity analysis of steel frame structure comprising non-compact sections. Eng Struct 2000;22:901-19. http://dx.doi org/10.1016/S0141-0296(99)00038-3.

[40] Uriz P, Mahin S. Toward Earthquake-Resistant Design of Concentrically Braced Steel-Frame Structures, Pacific earthquake engineering research center, PEER; 2008/08.

[41] Kanyilmaz A. Validation of fiber-based distributed plasticity approach for steel bracing models. Civ Eng J 2015;1:1-13

[42] Nguyen P, Kim S. Distributed plasticity approach for time-history analysis of steel frames including nonlinear connections. JCSR 2014;100:36-49. http://dx. doi.org/10.1016/j.jcsr.2014.04.012.

[43] Kanyilmaz A, Castiglioni CA. Performance Of Multi-Storey Composite SteelConcrete Frames With Dissipative Fuse Devices. COMPDYN 2015-5th ECCOMAS Themat. Conf. Comput. Methods Struct. Dyn. Earthq. Eng., 2015, p. 334-48.
[44] Kanyilmaz A. Inelastic cyclic numerical analysis of steel struts using distributed plasticity approach. COMPDYN 2015-5th ECCOMAS Themat. Conf. Comput. Methods Struct. Dyn. Earthq. Eng., National Technical University of Athens; 2015, p. 3663-74.

[45] Strand7 Pty Ltd., Strand7 Pty Ltd. www.strand7.com 2014

[46] EN 1993-1-1, European Standard. Eurocode 3: Design of steel structures - Part 1-1: General rules and rules for buildings. Eurocode 3 2005;1:91 pp.

[47] Eurocode C. Design of structures for earthquake resistance-Part 1: General rules, seismic actions and rules for buildings (EN 1998-1: 2004). Eur Comm Norm Brussels 2004; 1 .

[48] NTC. NTC 2008, Decreto Ministeriale 14/1/2008 - norme tecniche per le costruzioni. Ministry of Infrastructures and Transportations, Gazzetta Ufficiale S.O. no.30 on 4/2/2008 (2008). 2008:428.

[49] Elghazouli A, Castro JM, Izzuddin BA. Seismic performance of composite moment-resisting frames. Eng Struct 2008;30:1802-19. http://dx.doi.org/ 10.1016/j.engstruct.2007.12.004.

[50] Hsiao PC, Lehman DE, Roeder CW. Evaluation of the response modification coefficient and collapse potential of special concentrically braced frames. Earthq Eng Struct Dyn 2013;42:1547-64. http://dx.doi.org/10.1002/eqe.2286.

[51] Sohne M. MAURER Seismic Isolation with Sliding Isolation Devices for Bridge Structures 2012:1-16.

[52] Roussis PC, Constantinou MC. Uplift-restraining Friction Pendulum seismic isolation system. Earthq Eng Struct Dyn 2006;35:577-93. http://dx.doi.org/ 10.1002/eqe. 545

[53] Roussis PC. Study on the effect of uplift-restraint on the seismic response of base-isolated structures. J Struct Eng 2009;135(12):1462-71. http://dx.doi. org/10.1061/(ASCE)ST.1943-541X.0000070.

[54] Masi A., Vona M., La definizione dell'input sismico per gli scenari di danno e per la progettazione, Workshop DPC Workshop DPC-INGV-RELUIS, Villa Orlandi Orlandi, Anacapri Anacapri, 12-13 giugno; 2006.

[55] Erberik MA, Elnashai AS. Fragility analysis of flat-slab structures. Eng Struct 2004;26:937-48. http://dx.doi.org/10.1016/j.engstruct.2004.02.012.

[56] Kircher C, Nassar A, Kustu O, Holmes WT. Development of building damage functions for earthquake loss estimation. Earthq Spectra 1997;13(4):663-82.

[57] Ouvert AP. CONSEIL DE L' EUROPE Cahiers du Centre Européen de Géodynamique et de Séismologie European Macroseismic Scale 1998. vol. 15. 1998. 